\title{
Cancer stem cells and addicted cancer cells
}

\author{
Meike E. W. Logtenberg ${ }^{1}$ and Johannes Boonstra ${ }^{1,2^{*}}$ \\ *Correspondence: J.Boonstra@uu.nl \\ ${ }^{1}$ University College Utrecht, Campusplein, Utrecht, Netherlands. \\ 2Department of Biology, Utrecht University, Netherlands.
}

\begin{abstract}
Advanced tumors represent a genetically heterogeneous population of cells, which compromise subpopulations with distinct properties. Research indicates that a specific population of cells within the heterogeneous population contain stem cell-like properties. These 'cancer stem cells' are much like normal stem cells and have the capacity to self-renew, sustain the entire cancerous tissues and provide a reservoir of cells for recurrence after therapy and drug resistance. Cancer stem cells can arise from normal, adult stem cells, from progenitor cells or from fully matured cell types. They are likely generated by the process of epithelial-mesenchymal transition, through which differentiated cells acquire stem-cell like properties. This process potentially underlies the mechanism by which metastases evolve. Furthermore, mutations may render cancer cells dependent on the activity of one or more specific signaling pathways in the cell. This phenomenon is termed 'oncogene addiction' and represents the Achilles' heel of the cancer cell. As the concept of oncogene addiction in tumor cells proves to be very complex, additional models have been proposed to account for the variations in pathway dependencies and their intricate interactions. The combined knowledge concerning cancer stem cells, oncogene addiction and drug therapy resistance may lead to the identification of new avenues to improved drug strategies that address tumor heterogeneity and mechanisms of escape.
\end{abstract}

Keywords: Cancer stem cells, oncogene addiction, heterogeneous, tumor

\section{Introduction}

Cancer is one of the most devastating illnesses in humans. Despite many efforts in understanding the biology and genetic basis of cancer, progress in controlling and eliminating the disease, particularly in advanced metastatic stages, has been modest [1]. Pivotal questions like 'what signaling pathways are involved in tumor cell growth' and 'what causes tumor cell heterogeneity and metastasis' have only partly been answered. A better understanding of these fundamental processes fuel the hope that more effective, targeted cancer therapies can be designed aimed at preventing the progression to a metastatic stage [2].

Tumors from different patients exhibit extensive heterogeneity regarding their morphology, phenotype, genetic alterations, cell proliferation kinetics and responses to therapy [3]. In addition, significant differences exist among cells in an individual tumor as a result of tumor 'evolution' in which individual cells in the tumor mass continue to accumulate mutations. A recent hypothesis-proposes that distinct cells in a tumor exist that have a cancer-initiating capacity. These so-called cancer stem cells (CSCs) are thought to be the source of tumor heterogeneity during evolution of the tumor and the primary targets of selective forces that lead to improved growth properties and the capacity to metastasize $[1,4]$. CSCs have been proposed to originate from normal stem cells or more differentiated cells and possess or have reacquired distinctive capacities, including self-renewal and the ability to give rise to more differentiated cell types [5]. Understanding the distinction between CSCs and normal stem cells and normal tumor cells is critical to appreciate their central role in tumorigenesis and to design improved therapies for cancer patients.

Over the past decade, the focus of cancer therapy has shifted from cytotoxic chemotherapy to targeted cancer therapy [6]. Targeted cancer therapy may exploit the principle of 'oncogene addiction', more specifically the concept that some cancers are dependent on specific mutations to maintain their proliferation and survival capacities [6]. In addition, understanding whether CSCs have a specific role may also result in improved anti-cancer therapies. In this review, the concepts and consequences of CSCs and oncogene addictions of cancer cells will be discussed.

\section{The evolution of tumors and tumor heterogeneity Clonal evolution and heterogeneity}

In 1976, Peter Nowell proposed that the progression of tumors can be portrayed as an evolutionary process. This process is driven by the accumulation of mutations with a stepwise selection of cells that have a growth advantage [7]. Development of a so-called 'cancer-clone evolution' occurs in the tissue where the cancer first evolves. Tumors evolve from benign to malignant by acquiring mutations over time. The first mutation, called the 'gatekeeping' mutation, provides a cell with a selective growth advantage compared to normal cells, enabling it to outgrow other cells in its environment [8]. This is exemplified in colon cancer, whereby gatekeeping 
Logtenberg et al. Oncology Discovery 2013,

http://www.hoajonline.com/journals/pdf/2052-6199-1-7.pdf

doi: 10.7243/2052-6199-1-7

Table 1. Types of heterogeneity and examples.

\begin{tabular}{lll}
\hline Tumor suppressor hypersensitivity & Definition & Example \\
\hline Intertumoral heterogeneity & Variation among different tumors in the same organ & Breast tumors associated with BRCA-1 deficiency in mouse models \\
Intratumoral heterogeneity & Variation among cells in a primary tumor & Advanced human colorectal adenocarcinoma \\
Intermetastatic heterogeneity & Variation among different metastatic lesions in the same patient & Colorectal liver metastases \\
Intrametastastic heterogeneity & Variation among cells in a single metastatic lesion & Colorectal tumors with mutated and non-mutated KRAS \\
\hline
\end{tabular}

mutations most often occur in the APC gene. The cancer that results from a mutation in this gene grows slowly. A second mutation in another gene, for example in the KRAS gene, normally encoding for GTPase KRAS which participates as an essential regulator in many signaling transduction pathways, results in accelerated growth $[9, \mathbf{1 0}]$. The amount of cells that contain only a mutation in the APC gene is small compared to the amount of cells that contain mutations in both APC and KRAS genes. During accelerated expansion to large cell numbers, additional mutations accumulate in genes such as PIK2CA, SMAD4 and P53. Eventually, a malignant tumor is generated which has acquired the capacity to invade the basement membrane and metastasize to more distant sites [11].

The complexity of the mutations reflects a 'trial and error' process in cancer cells, in an attempt to cope with the constrains and pressures from the microenvironment [8]. Negative selective pressures slow down tumor growth, such as limited resources and environmental architecture limit the size of solid tumors at every stage of their progression [12]. A 'natural selection' takes place within the tumor through the competition for space and resources, resulting in adaptive traits or phenotypic changes in the cancer cells. For example, cells may no longer be subject to contact inhibition or inhibit competitors themselves, may acquire the ability to bypass apoptotic signals to prevent cell death, secrete soluble factor that initiate blood vessel formation (angiogenesis) or prevent immune cells from attacking the tumor cells [12].

Most cancer cells have multiple recurrent mutations that can be defined as 'driver mutations'. Driver mutations are specific mutations that give a selective growth advantage to the cell in its microenvironment, compared to cells that do not contain these driver mutations [8]. The existence of driver mutations was discovered by observations that these mutations occur more frequently in cancer cells than would have been expected based on calculations that predict the frequency of non-selective mutations [1]. Driver mutations are typically associated with extensive clonal expansion and have an impact on distinctive signaling pathways in cells. The complex genotype of the cells provides particular adaptive phenotypes that can directly or indirectly result in enhanced survival and proliferative activity [13]. A mutation can contribute or even determine the ability of a cancer cell to interact with the microenvironment, whereby additional growth advantages are stepwise introduced. The most rapidly dividing cell, with its driver mutations, leads the progression of the tumor. There is a difference between a driver gene and a driver gene mutation. A driver gene may contain both driver mutations and 'non-driver' mutations [8]. For example, the APC gene is defined as a driver gene. However, only mutations that truncate the encoded protein within its $\mathrm{N}$-terminal amino acids are considered driver mutations, because they confer selective growth advantage to the cell. Other non-driver mutations in the gene do not result in a selective growth advantage of the cell, such as mutations that are selectively neutral ('passenger' mutations) and mutations that are disadvantageous in the process of clonal selection $[\mathbf{1 , 8}]$. Passenger mutations have no effect on the formation and progression of a tumor. They are only identified in a context-dependent manner, which means that their phenotypic effects are only observed under specific circumstances. For example, the function of the gene can only be altered when the second allele of the same gene is lost, when another gene is also mutated or when it is involved in therapeutic responses whereby this specific gene is relevant [1]. Mutations that interfere with processes as DNA repair and apoptosis ultimately lead to chromosomal instability. These events are associated with accelerated accumulation of genetic defects, including an abnormal number of chromosomes ('aneuploidy'). This marks the switch to a tumor with a high number of dissimilar genotypes and rapidly provides the cells with the properties that are needed for tissue invasion and metastasis [14]. The emergences of adaptive traits or phenotypic changes in cancer cells that result from the selective pressures represent the so-called 'hallmarks of cancer' [13].

Phenotypic and functional variations among tumor cells can arise within a tumor and within different organs. The term 'heterogeneity' is used to describe these variability's. Various sub-forms of heterogeneity can be discerned, summarized in (Table 1). 'Intertumoral heterogeneity' refers to variation between tumors that arise in the same organ. Typically, tumors are characterized by their expression of specific markers (such as the expression of hormone and growth-factor receptors) and their molecular profile. Various tumor-subtypes can arise in the same tissue with different expression patterns. Tumorsubtypes can be primarily determined by mutations in the cell-of-origin, whereby different mutations result in different tumor morphologies, see (Figure 1a). Alternatively, different populations of cells in a lineage hierarchy may serve as the cells of origins for cancer sub-types that arise in the same organ or tissue, see (Figure 1b) [15]. Intertumoral heterogeneity 
a. Genetic mutation model
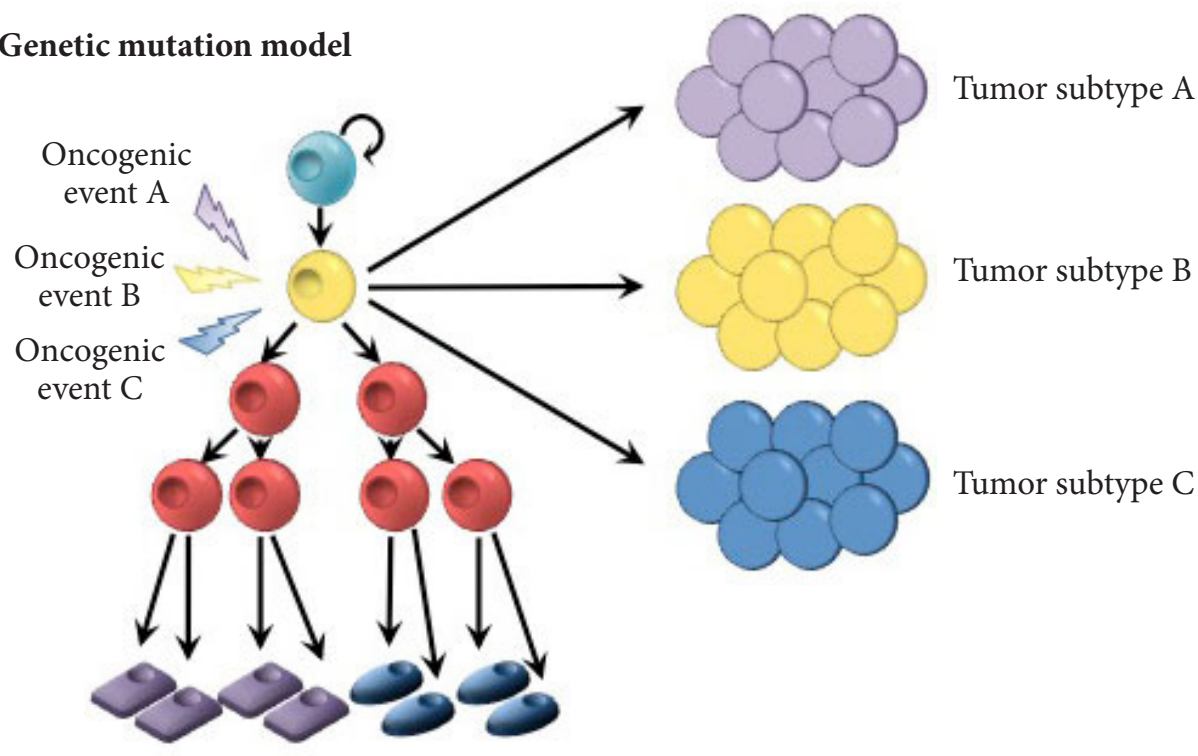

Tumor subtype B

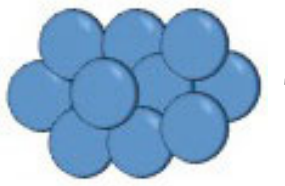

Tumor subtype C

b. Cell-of-origin model
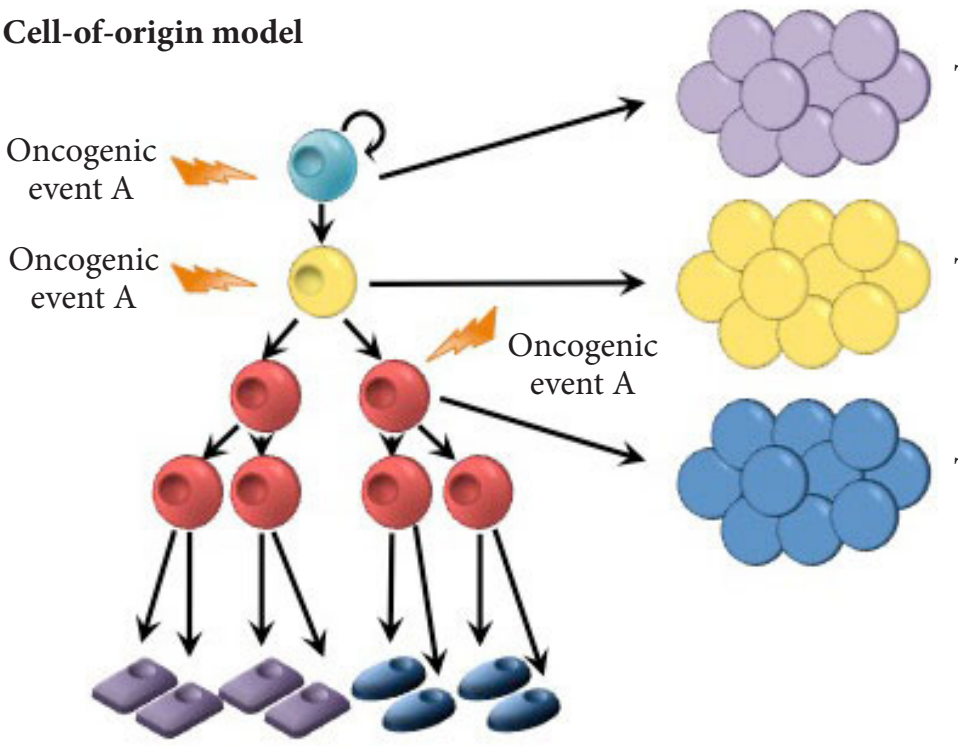

Tumor subtype A

Tumor subtype B

Figure 1. Models for intertumoral heterogeneity. (a) In the first model, genetic mutations determine the phenotype of the tumor. Different mutations lead to different molecular profiles, expression of specific markers and morphologies. (b) In the second model, different cell population serve as the cells of origin for the different cancer subtypes that arise within an organ or tissue. (as has been described previously [15])

is shown in a study that describes the inability to identify a single marker for a specific response to docetaxel and cisplatin in a mouse model for breast cancer associated with BRCA1 deficiency using genome-wide expression profiling. Tumors in the mouse models originated from deletion of BRCA-1 and P53. The differences observed between the tumors are the result of different mutations that arise during their development. Consequently, these differences result in distinct sensitivities to docetaxel and cisplatin in individual tumors [16]. Studies on human cancers have highlighted the role of specific genetic aberrations that contribute to tumor behavior [8]. The oncogene addiction hypothesis dictates that maintenance of the tumor phenotype depends on the continued expression of certain oncogenes. In addition, lineage-dependency oncogenes, which are dependent on the expression of certain lineage pathways in the cell, further contribute to heterogeneity. These phenomena and their relation to maintaining the tumor phenotype will be discussed later in this paper.

'Intratumoral heterogeneity' refers to variation within a single 
Logtenberg et al. Oncology Discovery 2013,

tumor and has been recognized for decades. As discussed, a tumor is comprised of cells that exhibit distinct capacities in proliferation and differentiation due to the process of clonal selection $[1,15]$. Populations of supporting, dividing, differentiating and degenerating cells form an integrated tumor mass [17]. Intratumoral heterogeneity and its extent has been demonstrated in a study on advanced human colorectal adenocarcinoma, where $67 \%$ of the analyzed tumors were heterogeneous for at least 1 mutation, with 2 until 6 different clonal genotypes per tumor [18]. Each time a tumor cell divides it may acquire new mutations. The number of mutations that distinguishes any two cells marks the time that has passed since they originated from their founder cell [8].

'Intermetastatic heterogeneity' describes the differences between metastatic lesions in the same patient. It is common that 20 clonal genetic alterations exist in one metastatic lesion that are not shared by other metastases in the same patient $[19,20]$. These mutations occurred in the founder cell of the metastasis: the cell that escaped from the primary tumor and initiated the formation of a metastasis elsewhere. Founder cells can differ substantially as they could have been present in different areas in the primary tumor, which is characterized by intratumoral heterogeneity [8]. Heterogeneity between multiple metastases in a single patient has been demonstrated for colorectal liver metastases. In a study that Goasguen and colleagues [21] conducted to predict chemosensitivity of tumors, patients were tested for both intermetastatic and intrametastatic heterogeneity. Significant levels of heterogeneity for allelic losses, mRNA levels expression and in vitro response to chemotherapy has been demonstrated both in single metastases and between different metastases in the same patient [21].

Finally, 'intrametastatic heterogeneity' refers to differences between cells of an individual metastasis. As discussed, the mutated founder cell initiates the formation of a metastasis at a different location. New mutations are added with each cell division as the metastasis grows and contributes to differences among cells in the tumor. Due to intrametastatic heterogeneity, metastatic lesions contain cells that are resistant to different drugs [8]. Intrametastatic heterogeneity and the development of resistance to drugs have been demonstrated for colorectal cancer. Colorectal tumors with non-mutated KRAS genes are often sensitive to EGFR blockade with antibodies. However, resistance to this blockade occurs frequently and results from rare cells that contain mutations in the KRAS genes [22]. These cells have been shown to pre-exist at low levels among with non-mutated KRAS cells, demonstrating heterogeneity in the metastatic lesion [22].

\section{Driver genes and signaling pathways}

The enormous variation in number and distribution of mutations that have been observed in cancer cells does not imply that tumor cells actually have an equally large number of possibilities to undergo a malignant transformation. More than $99.9 \%$ of the genomic alterations in tumors do not contribute to tumorigenesis [8]. These genomic alterations are the result of passenger mutations that emerge during cell divisions of tumor cells. In normal cells, genetic alterations also occur during interphase. When such alterations arise, control mechanisms induce apoptosis as a protection against cancer. In contrast, in cancer cells these alterations are tolerated due to mutations in genes such as P53 [23]. The tumor-suppressor protein $\mathrm{p} 53$ causes an arrest of cell cycle progression following DNA damage and other types of cellular stresses [24].

Over the past few years, driver genes in tumors have been identified by major tumor sequencing projects. Distinguishing driver genes from passenger lesions is challenging and requires complex approaches. How frequently a mutation occurs is determined by comparing its frequency to the background mutation rate [1]. This rate is estimated based on silent mutations that do not change amino acid encoding and which are therefore considered to be passenger mutations [25]. Different types of mutations have a different impact on protein function. A driver gene is expected to have more types of mutations that disrupt its protein function, such as frameshift indels, nonsense mutations and mutations in splice sites. According to the expected impact of their mutations on protein functions, genes with more 'driver-like' mutations are distinguished from genes with less 'driver-like' mutations by assigning different scores for following calculations [25]. Whether the mutation is associated with clonal expansion and whether the gene with the driver-like mutations is involved in known cellular processes that are relevant to oncogenes is also investigated [1]. To date, mutations in only 138 genes have been identified that, directly or indirectly lead to a selective growth advantage, classifying them as driver genes [8]. This growth advantage can be obtained only through mutations in a limited number of signaling pathways. The driver genes can be organized in one or more of the 12 pathways that can be classified into three cellular states they affect, see (Figure 2).

The first cell state is cell proliferation/differentiation and is based on differences between dividing and differentiating cells. The majority of mutations result in a shift in the balance between division and differentiation, in most cases favoring division. This shift leads to a selective growth advantage, because cells that differentiate eventually die or become quiescent [8]. Pathways such as APC, Hedgehog and NOTCH function by determining cell fate [26].

The second cell state that can be affected is 'cell survival'. The microenvironment that surrounds cancer cells cannot keep pace with the abnormally dividing cancer cells leading, among others, to insufficient supply of nutrients. This may be the result of the twisted structure of newly formed vessels in cancers. Not all cancer cells are in close contact with a capillary as normal cells, which are always within $100 \mu \mathrm{m}$ of a capillary [27]. Therefore, a cancer cell that acquires mutations that convey higher proliferative capacity under limiting nutrient concentrations will have a growth advantage over 


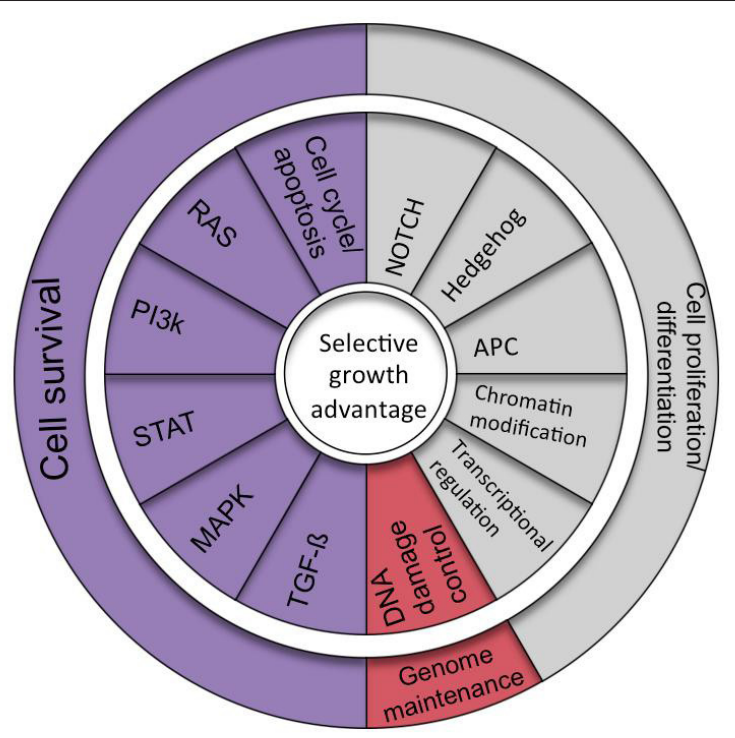

Figure 2. Signaling pathways and the regulated cellular processes. 12 driver genes can be classified in 12 pathways (middle ring). These pathways can be further organized depending on the cellular processes they regulate (outer ring). These pathways with the processes result in a selective growth advantage of a cancer cell. (as has been described previously [8])

other cancer cells in this environment that did not acquire these mutations. Such mutations can occur in the genes EGFR, HER2, FGFR2, PDGFR, TGF- $\beta$ R2, MET, KIT, RAS, RAF, PIK3CA and PTEN [8]. These genes encode receptors for growth factors or components of signal transduction cascades induced by growth factors and stimulate growth upon activation [28].

The third cell state is 'genomic maintenance'. Cancer cells are often exposed to toxic substances, such as reactive oxygen species (ROS), produced by the microenvironments in which they are present. ROS are produced by mitochondria and can react with oxygen to ultimately produce hydrogen peroxide and hydroxyl radicals, potentially damaging the cell. To prevent oxidative damage, scavenger systems and enzymes protect the cells from the attack by ROS [29]. Under normal conditions, ROS have important roles in signaling and homeostasis in the cell. However, access ROS can induce irreversible damage to components of the cell, leading to apoptosis and cell death $[29,30]$. Even without these poisons from the environment, cells make mistakes during DNA replication or cell divisions. Checkpoints exist that eliminate or inhibit cells that make mistakes [24]. Mutations in genes that are involved in the regulation of these checkpoints are often present in cancer cells, such as tumor suppressor gene P53 and ATM. ATM codes for ataxia-telangiectasia kinase that phosphorylates proteins in response to cellular stresses, leading the activation of cell cycle checkpoints and consequently to cell cycle arrest, DNA repair or apoptosis [31]. Defects in these genes can also result in a selective growth advantage by allowing cells with chromosomal alterations that favor growth to survive and divide. Understanding these different pathways is important for understanding the progression of tumors and their role in specific cellular processes has been crucial to understand heterogeneity among patients [8].

In certain cancers, cells that contain specific properties are critical for tumor initiation and growth and occupy the apex of the cellular hierarchy within a tumor [32]. These properties resemble the properties that are characteristic for stem cells. First, normal adult stem cells and their characteristics will be discussed, followed by the 'cancer stem cell hypothesis' which assigns a crucial role for cancer stem cells in tumor progression and evolution.

\section{The 'cancer stem cell' hypothesis}

\section{Adult stem cells}

Stem cells are defined as undifferentiated cells that adhere to two essential principles. The first principle describes the ability of a stem cell to 'self-renew', i.e., undergo symmetric division to give rise to two identical daughter cells with the same stem cell characteristics. The second principle describes the ability of a stem cell to undergo asymmetric division, hereby ultimately differentiating into more specialized cells giving rise to differentiated cell lineages. During asymmetric division, two different cells are eventually produced: one stem cell and a more differentiated cell with limited self-renewal potential. Regeneration within tissues requires regulation of stem cells that favor self-renewal. In contrast, homeostasis requires regulation of stem cells that results in a state where self-renewal and differentiation are well balanced [22].

Adult stem cellsare found throughout the body and are crucial in all multicellular organisms for physiological tissue 
Logtenberg et al. Oncology Discovery 2013,

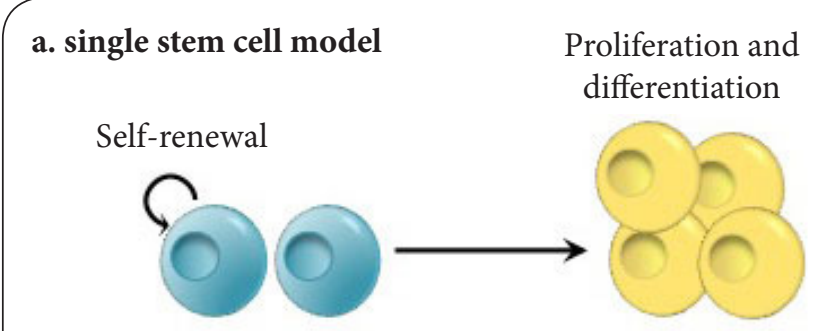

b. Two stem cells populations model
Inhibitory zone
Stimulatory zone

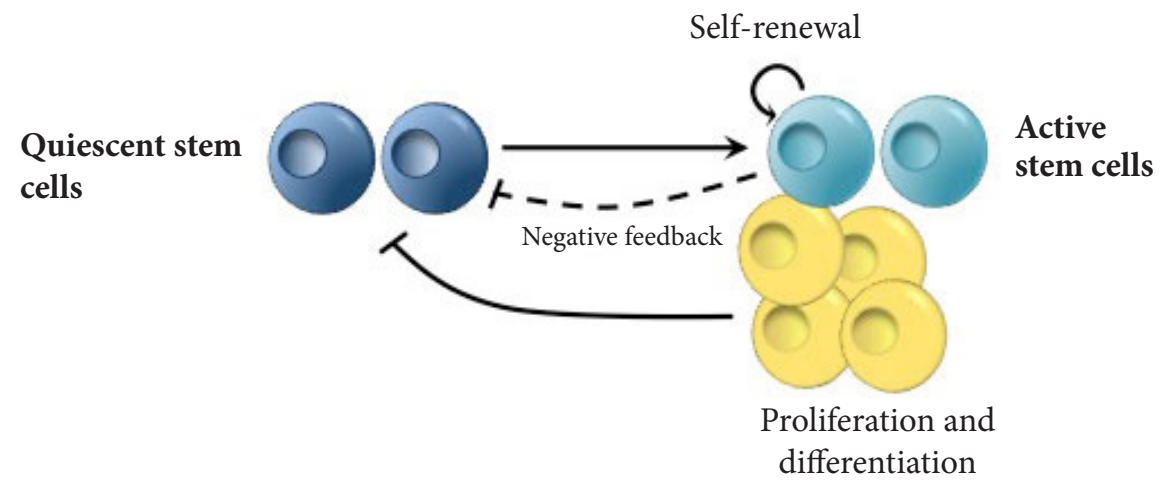

Figure 3. Models for stem cell-based tissue self-renewal and regeneration.

(a) Single stem cell model', previous model whereby a single stem cell population with both symmetric and asymmetric division maintains the balance between self-renewal and differentiation. (b) 'Two stem cell populations model' with quiescent stem cells serving as a reservoir for active stem cells, which proliferate and differentiate into more specialized cells. (as has been described previously [34])

renewal and regeneration after injury. The first model to describe adult stem cells proposes that asymmetric division in one stem cell population is key to maintain the balance between self-renewal and differentiation, see (Figure 3a). An important feature of adult stem cells is their relative proliferative quiescence, meaning they are largely out of the cell cycle and in a lower metabolic state $[34,35]$. The cells are mainly in the $G_{0}$ or $G_{1}$ phase of the cell cycle and a majority has exited the cell cycle completely, resting in $\mathrm{G}_{0}$ phase [35]. Although adult stem cells are considered to be 'immortal', they can obtain DNA damage or experience early exhaustion during proliferative stress. The quiescent state of adult stem cells is believed to protect the stem cell pool from stress-related exhaustion [35]. The recent identification of actively cycling adult stem cell populations in mammals has challenged the view that the quiescent state is a hallmark feature of stem cells and suggests an alternative model of stem cell divisions [34]. According to this view, a reservoir population consisting of quiescent stem cells and actively cycling stem cells co exist in the same organs [34]. The cycling stem cells perform daily tasks in tissues, see (Figure 3b) [34]. This so-called 'zoned' model proposes that active adult stem cells account for most of the replenishment of corresponding tissues by undergoing asymmetric division, whereas the slow-dividing stem cells mostly undergo symmetric cell division and serve to replenish the reservoir of actively dividing stem cells. The slow-dividing stem cells replace damaged active stem cells and conversely, active stem cells may replace the slow-dividing stem cells. A negative feedback mechanism is proposed from the active stem cell pool to the quiescent stem cell pool that prevents over-activation of these cells.

To control the balance between self-renewal and differentiation of adult stem cells, important signaling pathways involved in normal development operate in a complex interplay. These signaling pathways, including the Wnt, the Notch and the BMP pathways, provide stimulatory and inhibitory signals [34]. The pathways contribute to the two different states of stem cell populations (quiescent state and active state) at adjoining locations by secreting different proteins in isolated zones. The proteins determine the state of the stem cells [34]. 
During asymmetric division, stem cells typically give rise to differentiated cells with a limited lifespan, often referred to as progenitor cells. In the zoned model, the active stem cells divide into progenitor cells that are subsequently able to differentiate into mature cells [36]. The progenitor cells constitute a compartment that serves to expand the cell pool available for supplying the host tissue with various functional lineages by rapid cell division. Optimal functionality in the host tissue is ensured by the restricted lifespan of the terminally differentiated mature cells, which are derived from the progeny compartments [36].

\section{The 'cancer stem cell' hypothesis}

In depth understanding of the mechanisms that drive morphological and behavioral heterogeneity of tumors is crucial for the development of more effective cancer therapies. In the past decade, interesting theories and insights concerning the role of stem cells in cancer have emerged. The 'cancer stem cells' (CSC) hypothesis proposes that a small number of stem-like or tumor-propagating cells produce differentiated cells, which subsequently make up the body of the cancer [37]. These stem cell-like cells are termed cancer stem cells (CSCs) and are thought to maintain and re-populate the cancer. Currently, the widely accepted definition of CSCs is 'a cell within a tumor that possess the capacity to self-renew and to cause the heterogeneous lineages of cancer cells that comprise the tumor' [38].

Valent and colleagues [39] proposed a more detailed description for CSCs. Neoplasia is a term used to describe all situations where abnormal division or growth of cells occurs. Both pre-malignant and malignant conditions include the appearance of clones of cells as a result of distorted growth. Malignant conditions are characterized by a greater clonal instability. Pre-malignant conditions are usually un-predictable, however they have no immediate cancer-generating potential. Pre-malignant situations can potentially progress into a malignant situation with more invasive characteristics. A similar distinction for stem cells with distorted growth properties has been proposed. Both pre-malignant and malignant stem cells can be described as neoplastic stem cells with the ability to maintain a population of neoplastic cells, but only malignant stem cells have the ability to produce an invasive tumor mass or leukemia. Therefore, malignant neoplastic stem cells are defined as CSCs [39]. Throughout this review, the latter detailed definition of CSCs will be used.

CSCs are distinguished from other cells that comprise a tumor by their exclusive ability to continue the growth of a malignant cell population to an indefinite extent, which emphasizes the importance of focusing on targeting CSCs in new cancer therapies [39]. Where stem cells in normal tissues are defined as undifferentiated cells with the capacity to produce the specialized cells that compromise the tissue, CSCs define specialized populations of cells in tumor tissue that are responsible for the growth and recurrence of the tumor $[17,38,39]$. During the evolution of a malignant tumor, alterations that result from mutations and epigenetic changes lead to deregulated cell production and clonal expansion. Ultimately, malignant tumor cells may be produced that have acquired a complex profile of distortions and lost many features that are typical for differentiation in normal tissues [39]. Several characteristics are shared by CSCs and normal adult stem cells, including the expression of primitive stem cell markers and human telomere reverse transcriptase (hTERT) [40]. Moreover, CSCs have an increased expression multidrug resistance transporters and DNA damage repair enzymes [17].

Insights in the existence of CSCs evolved from research on acute myeloid leukemia (AML). Leukemic cells were shown to be derived from precursor cells in the bone marrow. In AML, all leukemic cells were found to contain one specific mutation in their genome, designated as the 'leukemia initiating mutation' [3]. During the progression of the disease, more mutations were added. Investigation on leukemic cells present in the blood revealed that the majority had lost the capacity to divide. Only a small group of cells was capable of dividing and initiating a novel leukemia in mice [41]. These cells were termed 'leukemia-initiating cells' and they closely resemble normal multi-potent blood stem cells [41].

The blood stem cells are rare in the bone marrow and like all stem cells, have the capacity to self-renew and give rise to progenitor cells for the various types of blood cells. The leukemia initiating cells appeared to be highly resistant to chemotherapy and are thought to be the cause of recurrence of AML after therapy. Their nature enables them to self-renew and rapidly replenish a population of leukemic cells [3]. In addition, a specific hierarchy among leukemic cells was discovered [42]. A small number of leukemia initiating stem cells generates a larger population of rapidly dividing progenitor cells. These progenitor cells become more differentiated and ultimately give rise to malignant mature cells [3]. This hierarchy of leukemic stem cells again resembles the normal blood cell hierarchy. After the identification of leukemic stem cells in patients with AML, similar roles for stem cells in solid cancers were discovered with the help of mouse models that allowed human cancer cell transplantation [14].

The self-renewal capacity of CSCs is enforced by their aberrant genotype and other, epigenetic features. CSCs are thought to change their genotype and phenotype before and after cancer therapies. In addition, it is very likely that some therapies provide a selection for CSC survival and proliferation, similar to clonal selection occurring within a solid tumor. Selective pressure enables the CSCs with the most extensive self-renewing capacity to survive during the progression of a tumor [1].

\section{Cell of origin and cancer stem cells}

The exact mechanism of CSC generation is unclear, although several hypotheses have been proposed [33]. The original concept of CSCs was based on the belief that the number of 
Logtenberg et al. Oncology Discovery 2013,

cell divisions that is required to produce a fully differentiated, non-dividing progenitor cell from a normal stem cell is not sufficient for the accumulation of an adequate number of mutations and rare events to produce a malignant phenotype [33]. In contrast to differentiated cells, long-lived stem cells that self-renew were believed to be candidates for acquiring sufficient alterations to establish a fully malignant cell population. As discussed above, stem cells contain two populations with continuously active mechanisms that enable controlled self-renewal. These mechanisms operate during the lifetime of an individual and are therefore susceptible to alterations for a long period of time. Mutations and rare events accumulating within these mechanisms can transform the stem cells, resulting in uncontrolled cell divisions that initiate tumorigenesis [33]. However, recent studies have suggested that CSCs can also arise by alterations of a progenitor cell or of a fully differentiated malignant cell type within a cellular hierarchy. Hereby, the cells are reactivated to a stem cell-like state through specific mutations activating the necessary pathways [1]. In the example of AML, the identification of the leukemic stem cells does not suggest anything concerning the origin of these cells [43]. The cells may have originated from a pool of original blood stem cells based in the bone marrow that contain the first leukemia-initiating mutations. When this is the case, the abnormal leukemic stem cells would represent the stem cell of origin of the leukemic disease, similar to the original concept of CSCs [41]. However, the leukemic stem cells could also represent leukemic blood cells that are first unable to self-renew and give rise to more differentiated cell types, but have reacquired stem cell-like characteristics due to specific genetic defects or interactions with their environment. In this case, the leukemic stem cells are CSCs that contain multiple mutations and therefore have regained their capability to self-renew. Consequently, they may also be responsible for leukemic progression and rapid recurrence after treatment [14]. A third possibility is that the leukemia stem cell population consists of a mixture of the two former cases, with CSCs derived from both blood stem cells and specialized cells [14].

Regardless of their origin, CSCs possess properties that distinguish them from the other cells in a tumor [44]. The genesis of CSCs involves the activity of stem cell transcriptional programs that result in the activity of 'stem ness genes'. These genes typically confer stem cell properties like self-renewal and are responsible for the behavior of stem cells by transcriptional and epigenetic regulation [14]. The distinction between the 'cell of origin' of a tumor and CSCs is important. The cell of origin is the first normal cell that acquires cancer-promoting mutation(s) [15]. This event does not have to be related to the CSCs, which is the cellular subset within the tumor that uniquely sustains malignant growth. The hierarchical organization observed in both leukemia's and solid tumors is very likely to be sustained by a subpopulation of CSCs, which are self-renewing and able to generate the full repertoire of tumor cells. Whether a cancer follows the proposed CSC model is likely determined by the cell of origin, the nature of the mutations this cell acquires and the differentiation potential of the cancer cells [15]. Chronic myelogenous leukemia (CML) is an example of a cancer whereby the initiating cell is a restricted progenitor cell. CML is characterized by the increased and unregulated proliferation of myeloid cells and the accumulation of these cells in the blood. In CML, a progenitor cell that is committed to become a granulocyte-macrophage may reacquire the stem cell-like capacity of self-renewal due to effects of specific mutations. Other examples of tumors whereby the cell of origin is a previously committed cell are medullo-blastomas, basal cell carcinomas and breast cancer associated with the BRCA-1 gene [15]. In contrast, in intestinal cancer, two distinct crypt stem cells have been identified as the first cellstoacquire cancer-promoting mutations [45]. The majority of colorectal cancers are caused by mutations in the Wnt pathway, resulting in the excessive Wnt signaling. Deletion of a specific regulatory gene in stem cells present in crypts of the intestine (the socalled 'Lgr5+ stem cells') has shown to result in intestinal cancer [45]. In addition, the stem cell or early progenitor cell has also emerged as the cell of origin in certain leukemias, glioblastomas in the brain and prostate cancer [15].

(Figure 4) illustrates the evolution of a CSC. The normal hierarchy comprises stem cells that generate more differentiated and restricted progenitor and mature cells. The accumulation of mutations in the cell of origin may result in the emergence of a CSC. As discussed, this CSC may arise from a normal stem cell, a progenitor cell or from a fully malignant cell type that has re-acquired stem cell-like characteristics. The CSC is the only cell in the tumor cell population that is capable of maintaining tumorigenesis.

In addition distinguishing between CSCs and cells of origin, the concept of CSCs should also not be confused with 'cancerous stem cells'. A cancerous stem cell is a term used to describe stem cells that become cancerous with uncontrolled division during the evolution of the tumor. However, during the formation of a tumor it is not assumed or required that the changes that lead to the establishment of a CSC occur in the original stem cell compartment of the affected tissue [33]. Therefore, a cancerous stem cell may or may not represent a CSC.

\section{Genesis of cancer stem cells and reactivated signaling pathways}

According to current thinking, CSCs originate from a switch involving the transformation of a polarized epithelial cell type to a non-polarized mesenchymal cell type [14]. This mesenchymal cell type contains stem cell properties, including migratory behavior and the capacity to self-renew and generate differentiated cells. Switching to a mesenchymal stem cell type occurs by a so-called 'epithelial-mesenchymaltransition' (EMT). EMT in the epithelium of an organ is possibly be an initial step during tumorigenesis. The loss of epithelial 


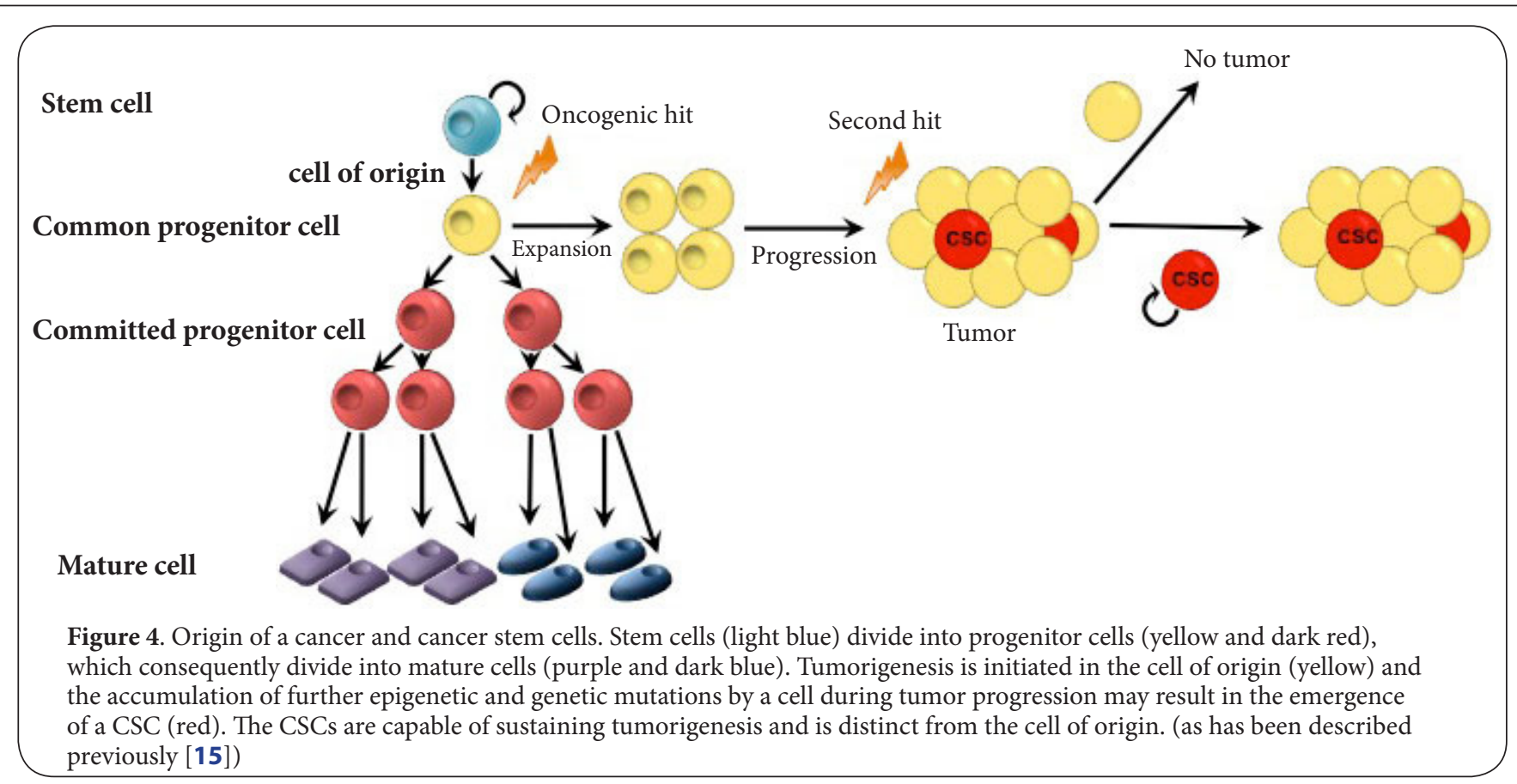

properties may be directly linked to the gain of CSC-like properties [46]. Three different subtypes of EMT processes exist. Type $1 \mathrm{EMT}$ is associated with embryonic development when tissue and organ structures are formed $[14,47]$. This physiological process enables cell migration to appropriate body locations in developing embryos. Type 2 EMT is involved in the process of wound healing, inflammation, fibrosis and the regeneration of tissue [47]. Type 3 EMT results in the formation of migratory mesenchymal cancer cells from differentiated epithelial cancer cells. This subtype may lead to cancer invasion and metastasis [48].

EMT is a multistage process and involves a large number of mutations and cellular plasticity. EMT results in dramatic changes in both the morphology of the cell and the adhesion molecules expressed on the cell surface. Furthermore, EMT involves an increase in invasive and migratory properties $[46,47]$. EMT is thought to allow cancer cells to avoid general immune defenses, cellular senescence, oncogene addition, anoikis and apoptosis [47]. The reversed process, mesenchymalepithelial transition (MET), also takes place during embryonic development and allows the differentiation to specialized epithelial cell types of the tissue or organ at a fixed site [49]. MET is possibly involved in the formation of metastases and will be discussed later in this review.

EMT proceeds in several steps resulting in cells with a spindle-shaped morphology [46]. Implementation of the process is dependent on the activity of several signaling pathways, which have to collaborate to efficiently induce the EMT program [50]. These include the MAPK, PI3K, Wnt/ $\beta$ catenin, NFKB, Notchand Hippo/Warts pathways [51]. During EMT, specific transcription factors are activated, such as
SNAIL and TWIST, which subsequently initiate a stem cell transcriptional program [50]. Expression of epithelial genes like E-cadherin is reduced, in contrast to characteristic mesenchymal "stemness" genes including Oct- 4 and Nanog [49]. The production of metalloproteases, such as MMP-2 and MMP-9, enables basal membrane and extracellular matrix degradation. Switching from $\mathrm{E}$-cadherin to $\mathrm{N}$-cadherin results in loss of cell-cell contact. Together, these events enable cell migration [49]. However, the exact molecular mechanisms enabling and controlling EMT in cancer and CSCs are not fully understood [14].

Stem-cell like characteristics can be reacquired by the reactivation of signaling pathways that are important in normal self-renewal programs, including the Wnt, Hedgehog, BMI-1, Notchand the TGF- $\beta$ pathways [52]. Therefore, it has been suggested that the same pathways have also a role in the generation of CSCs. As discussed, the reactivation of these pathways is probably due to the stimulation of an EMT-process that results in the transition of an epithelial to a mesenchymal cell type. Different types of disruptions can cause abnormal signaling in a cell. Some mutations can directly lead to abnormal activation of a signaling pathway. For example, the loss of the APC gene in colon cancer leads to activation of the Wnt pathway [53]. Alternatively, a genetic or epigenetic change leading to abnormal signaling can also be associated with enhanced responsiveness of a pathway to an otherwise normal presence of a ligand for its receptor. The loss of expression of a Wnt antagonist, such as the product of the DKK gene, is associated with gene promoter methylation [54]. In addition, the microenvironment of the cancer cell can also be responsible for inducing abnormal signaling 
Logtenberg et al. Oncology Discovery 2013,

pathway activation. Tumor-invading macrophages, other immune cells and activated fibroblasts produce a variety of growth factor ligands and cytokines in the microenvironment. These factors are normally not present in the tissue where the tumor emerged and are potentially capable of activating EMTinducing signaling pathways including the Wnt, Hedgehog and TGF- $\beta$ pathways [55].

Different lines of evidence suggest a role for the pathways in the generation of CSCs. The Wnt pathway normally controls cell proliferation and differentiation. Another role of the Wnt pathway in cancer, besides association with the APC gene loss in colon cancer, is seen in tissues where the Wnt pathway controls stem cells [45]. Malignant proliferation of the cells occurs when the tight regulation of the Wnt pathway is transformed in deregulated activation [45]. In addition, Wnt signaling is also linked to the DNA damage response found in primary human breast epithelial cells and to a parallel role in hematopoietic malignancies, where it is essential for the renewal of chronic myeloid leukemia stem cells [56]. The Hedgehog pathway is another key regulator during embryonic development, controlling proliferation and differentiation of cells in a temporal- and spatial-dependent manner. Hereby, developing tissues reach their correct size with the appropriate cell types and adequate degree of vascularization and innervation [57]. When deregulated, the Hedgehog pathway contributes to the onset of tumorigenesis or accelerates the rate of tumor growth [57]. The BMI-1 pathway plays an important role in cell cycle regulation, cell immortalization and cell aging. In addition, recent studies have demonstrated that the BMI-1 pathway is involved in the regulation of self-renewal and differentiation of stem cells [58]. Overexpression of the BMI-1 pathway and mutations in the Hedgehog pathway are involved in the genesis of medulloblastoma, and Hedgehog signaling has been found to increase BMI- 1 expression in primitive neural stem cells or progenitor cells [56]. Autocrine TGF- $\beta$ signaling, normally involved in developmental roles in adults and embryo's, plays a role in the retention of the stem-cell state of glioblastoma cell by inducing the expression of transcription factors Sox4 and Sox2 [59]. Moreover, the conversion of glioma cells to a stem-cell like state is dependent on induction of Notch signaling in the cells [60]. The Notch pathway is believed to be deregulated in CSCs so that it leads to uncontrolled self-renewal of CSCs which are generating a tumor [61]. Deregulated Notch signaling and upregulated expression of Notch receptors and their ligands has frequently been observed in numerous types of cancer, such as renal carcinoma, lung cancer, cervical cancer, among others [61].

Physical parameters in the tumor may also play a role in the EMT process and be associated with metastatic behavior. When a tumor evolves, the physical forces in the microenvironment change, which consequently have effect on both cell and tissue behaviors. During the formation of the tumor, stromal cells that are associated with tumors are often recruited, differentiated or activated. These stromal cells include endothelial cells, mesenchymal stem cells, inflammatory cells, immune cells, fibroblasts and myofibroblasts [62]. The cells participate in remodeling the extracellular matrix of tumor cells and promote angiogenesis by providing the appropriate growth factors and signaling molecules [62]. Moreover, altered biochemical and mechanical signals can also result from components of the tumor stroma that are non-cellular. This includes collagens, fibronectin, tenascin and proteoglycans which are abnormally expressed and altered [62]. Such alterations can influence the phenotype and function of cells by activating the signaling pathway through, for example, the induction of conformational changes in membrane proteins. An example of membrane proteins that respond to changes in these forces are cell membrane-located integrin adhesion molecules [14]. In addition, TGF- $\beta$ and Wnt membrane receptors are also known to respond to force changes [14].

\section{Cancer stem cells and metastasis}

Metastases represent the final and often fatal step during progression of solid tumors [63]. It has been hypothesized that the CSCs are responsible for the generation of new tumors distant form the primary site, based on the demonstration that CSCs present in human breast cancers are able to generate both primary tumors in the breast of mice as well as secondary tumors in the lung $[4,64]$. In another, CSCs from human pancreatic tumors were placed in the pancreas of mice and shown to generate distant liver metastases [4]. Different CSC populations may be responsible for the different tumor sites.

Some distinct properties of CSCs make them likely candidates for mediating metastatic progression. It is thought that only CSCs and not normal tumor cells are able to initiate and sustain tumorigenesis, including the development of metastatic lesions. Normal tumor cells that lack stem-cell characteristics could potentially migrate, but are not able to produce the complex basis of metastases [65]. The plasticity of CSCs improves their chances to survive in a foreign environment, where growth factors and signaling molecules differ from those at the primary cancer site [66]. Plasticity may also facilitate the EMT process, possibly a key event in the early phase of metastasis [4]. This possibility will be discussed in more detail.

The ability of cells to migrate is a vital process during normal development and tumor cells appear to have acquired this capacity [4]. Cells in normal adult tissues maintain migratory capacity through their ability to generate an EMT process. Similarly, it has been hypothesized that CSCs are capable of activating migration through EMT. In addition to the $\mathrm{N}$-cadherin marker, the markers Fox $\mathrm{C} 2$ and Zeb factors have also been linked to CSC migratory state [67]. It was first suggested that the EMT process occurs in carcinoma cells proper, as it was demonstrated that tumor stroma which promote metastasis did not induce EMT in tumor cells [68]. Other studies suggested that the acquisition of an EMT may be regulated by signals from the microenvironment or niche. 


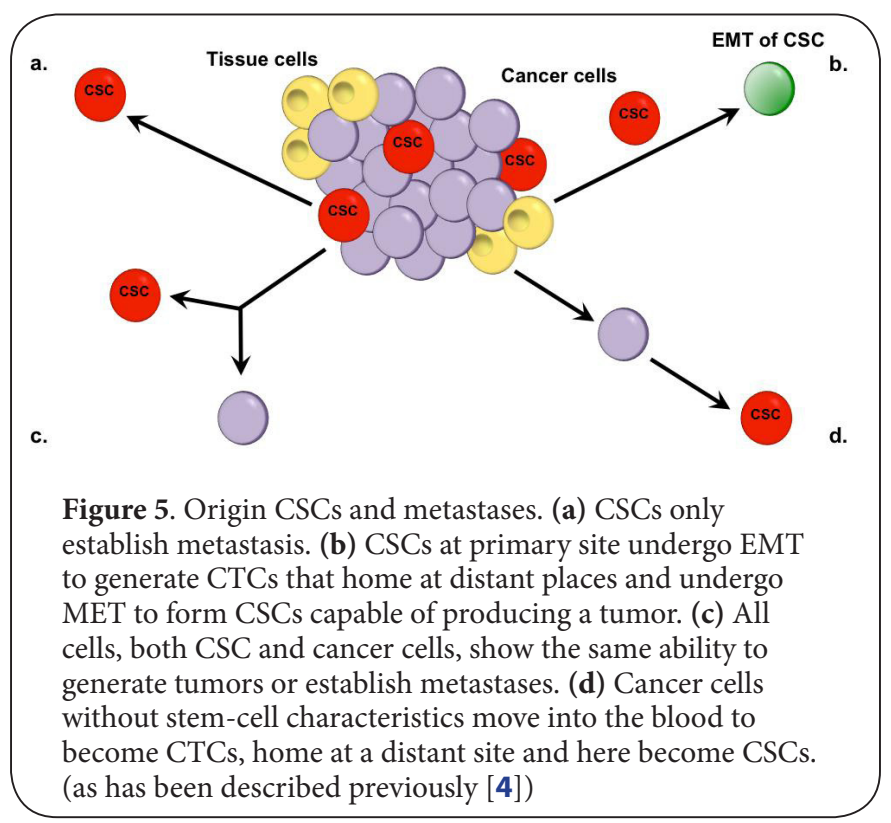

Tumor-associated fibroblasts or cancer-associated fibroblasts in breast cancers have been shown to enhance the potential of tumors to undergo a metastatic process. The fibroblasts promote migration through an EMT process, in addition to establishing CSC-like state in tumor cells $[69,70]$. Therefore, it seems that the stroma of tumor cells does have a role in the EMT process.

Other factors and molecules are also thought to participate in the process of metastasis facilitated by CSCs. One example is the protein Midbody. During cell division, the daughter cells must lose contact to generate independent cells. This step occurs within a singular organelle that is formed between daughter cells during cytokinesis. The protein Midbody is essential for this separation process and tumor cells have been shown to accumulate Midbody, likely contributing to their tumorigenicity [71]. Another example is microRNA-124. Loss of microRNA-124 (miR-124), which normally regulates cell proliferation, has been shown to promote glioma formation. Thus, miRNAs may participate in the activation of CSC-like activities [4]. Krueppel-like factor 4 (KLF4)is a protein which is used to 'reprogram' somatic cells into stem cell-like cells. KLF4 functions as an oncogene and is highly expressed in more than $70 \%$ of breast cancers [72]. In tumorigenesis, this protein has potent oncogenic activities and is possibly involved in maintaining stem cell-like features and promoting cell migration and invasion [72].

Furthermore, the expression of 'phosphatase and tensin homolog' (PTEN) has been demonstrated to be crucial for the establishment of a stem cell-like state. In prostate cancer, the loss of PTEN correlates with metastasis and disease progression [73]. The RAS/MAPK pathway, an important signaling pathway in normal cells, has been linked to PTEN deletion. RAS activation cannot initiate prostate cancer development. However, the progression is significantly accelerated upon PTEN loss and accompanied by EMT and metastases [74].

Cancer stem cells, circulating tumor cells and metastasis Other cells that have been linked to tumor progression are circulating tumor cells (CTCs) [4]. CTCs are defined as very rare cancer cells that are found in the blood circulation. CTCs can originate from primary and metastatic tumors and express specific markers on their cell membranes. These markers are used for their detection and isolation from non-epithelial blood cells. The markers include the cell adhesion molecule EPCAM and a component of the cytoskeleton, cytokeratin [14]. However, defining these cells by their marker expression pattern is not simple, since the cells are very heterogenous [75]. Some cells express mesenchymal and stem cell markers instead of EPCAM and cytokeratin, which includes vimentin, $\mathrm{N}$-cadherin, CD44 and ALD-1 [14,76].

Whether CTCs are only associated with tumor progression or whether they contribute directly to the metastatic process has not yet been determined. It is possible that a fraction of CTCs have CSC-activity. It has been hypothesized that some CSCs in a primary tumor enter the circulation and become 'circulating CSCs' or CTCs with stem-like properties [4]. These CTCs are CSCs that went through an EMT process in the tumor tissue and consequently migrated in the blood stream [14]. The self-renewal properties of the CTCs may initiate metastatic growth when positioned in a tissue with a micro environment that is suitable for supporting survival of the tumor cells and which provides the stimulation to induce clonal proliferation [14]. This has been demonstrated in xenotransplantation models, whereby CTCs were isolated from patients with melanomas. These CTCs were found to generate metastases in the models [77]. MET may establish the disseminated CSCs [4].

(Figure 5) gives an overview of the hypotheses concerning the origin of CSCs and their role of metastases. In one scenario, CSCs in primary tumors are able to home and metastasize to distant tissues. Another possibility is that the CSCs generated in primary tumors undergo EMT to generate CTCs, which home to distant tissues and undergo a MET process. In some tumor types, all the cancer cells (including CSCs) have the same ability to generate tumors or establish metastases in animal models. Lastly, cancer cells without stem-cell characteristics possibly move into to the blood circulation and become CTCs. Subsequently, they home to distant sites and reacquire stem-cell like characteristics, becoming CSCs and able to sustain tumor growth [4].

\section{The metastatic niche}

The finding that differentiated cells can be induced to revert to a pluripotent state and subsequently give rise to various differentiated cell types has suggested that in metastatic cancer, this form of plasticity in combination with stimuli 
Logtenberg et al. Oncology Discovery 2013,

from the microenvironment or metastatic niche may play a role in affecting the fate of CSCs [78]. CSCs are thought to home in a relatively stable microenvironment in order to retain their stem cell-like state and give rise to progenitors and more differentiated cells [4]. The tumor microenvironment is composed of extracellular components and immune and stromal cells [63]. Support for plasticity of tumor cells comes from the finding that the fibroblasts in a metastatic niche contain mutations that are identical to those found in the cancer cells [79]. Tumor-associated stromal cells express the transcription factor SNAIL which is activated in the EMT process [80]. Moreover, in melanoma cancer, markers have been found on cells with an endothelial phenotype. This phenomenon is called 'vascular mimicry' and suggests that these cells represent progenitor cells that have arisen from CSCs. Thus, tumor cell vasculogenic mimicry supports the plasticity of cancer cells to form vascular networks that are crucial for the formation and progression of metastases [81].The CSC may have been under the influence of angiogenic factors in the tumor microenvironment, resulting in the differentiation of an endothelial cell type [81]. Finally, some CTCs have been found to co-express specific cancer cell markers such as human epidermal growth factor receptor 2 (HER2) and CD45. This suggests that the CTCs have partially differentiated. This differentiation is along the hematopoietic lineage and could have been initiated as a result of a temporary residence in the bone marrow niche [82]. The bone marrow microenvironment has been known to be a regulatory site for hematopoietic function. Hematopoietic stem cells (HSCs) are believed to localize to specific microenvironment for self-renewal and differentiation into other cell types [83]. In conclusion, some CSCs have a higher plasticity than thought and the metastatic niche possibly contributes to the capability of CSCs to give rise to differentiated progeny. It has been thought that some cells may be educated within tumors to 'hunt for' niches at distant sites, a hypothesis currently under investigation [4].

\section{Addictions of cancer cells \\ Oncogene addiction and tumor suppressor gene hypersensitivity}

Cancer research has highlighted some common themes in the genesis and progression of tumors. First, cancer is caused by 'corrupted' cellular genes, so-called oncogenes, which cause the cell to survive indefinitely and proliferate aberrantly [84]. Second, the genesis and progression of tumors is governed by the activation and inactivation of specific genes [84]. Oncogenes are activated and positively affect the proliferation of cancer cells. In contrast, tumor suppressor genes are inactivated during the process of tumor formation. Loss of tumor suppressor genes through deletion, inactivating mutations or epigenetic silencing results in the removal of restraints of the cell and ultimately leads to tumorigenesis [84]. The evolution of a benign to an invasive and metastatic tumor is progressively driven by the accumulation of alterations in these genes with highly diverse functions [85]. Recently, a third theme has been investigated and emerged as possible target in cancer therapy. Dr. Bernard Weinstein was the first to propose that even though cancer cells contain multiple mutations, the cell is dependent on one or only a few genes for the maintenance of their phenotype [86-89]. The hypothesis of 'oncogene addiction' refers to the "Achilles' heel" of cancer cells, explaining the observation that a tumor cell can exhibit dependence on a single oncogenic pathway or protein for its sustained proliferation and survival, despite its diversity of genetic alterations. During the formation of a tumor, cancer cells become'addicted' to certain pathways regulated by driver mutations for their survival [90]. Inactivation of this driver oncogene in a tumor may result in growth arrest accompanied by differentiation, senescence or apoptosis [90]. In addition to being dependent on the existence of certain pathways, cancer cells can also be addicted to the absence of a pathway. This has been observed in cancer cells whereby activation of previously inactivated tumor suppressor genes endangers the survival of the cell. The phenomenon is termed 'tumor suppressor hypersensitivity' and describes the addiction of cancer cells to the in activation of tumor suppressor genes [91].

The validity of the oncogene addiction hypothesis is based on numerous experiments in genetically engineered mouse models and observations in patients, whereby the reversal of one or a few of the abnormal mutations in genes profoundly inhibited the growth of the cancer cells or even lead to the improvement of survival rates [88]. Inactivation of oncogenes can be achieved by various experimental methods, including RNA interference, inducible gene expression systems, small-molecule inhibitors, antibodies and dominant-negative interference [91]. An example of oncogene addiction is illustrated in mouse models with an inducible myelocytomatosis (MYC) oncogene [92]. MYC is a regulatory gene, coding for a transcription factor that plays an important role in regulating cell growth (by up-regulating ribosomal RNA and proteins), apoptosis (by down-regulating the regulatory protein $B C L-2)$, differentiation and stem cell self-renewal [92]. A mutated version of MYC causing overexpression has been found in many cancers. In mouse models with an inducible MYC oncogene, MYC-driven tumor cells including skin papillomas, lymphomas and osteosarcomas, can be reversed to normal cells upon the inhibition of the MYC oncogene [92-94]. Expression of MYC in normal cells has the opposite effect to oncogene addicted cancer cells: it induces apoptosis [90]. Oncogene addiction was also demonstrated in mouse models of melanoma and leukemia, whereby inhibition of the oncogenes Harvey Rat Sarcoma Virus oncogene(HRAS) and BCR-ABL, respectively, stopped the cancer from further proliferation and growth $[94,95]$. The HRAS gene codes for an enzyme that is important in many cellular processes. BCR and $A B L$ are two different genes and when fused due to a translocation, encode a mutant fusion protein known to have a role in the several forms of leukemia. 
In human colorectal cancer cells, oncogene addiction to the KRAS gene has been demonstrated, whereby removal of the gene in a knockout mouse model resulted in the reversion of the phenotype and revoked the ability of the cells to form tumors [96]. In normal cells, KRAS codes for a protein that performs an essential function in normal tissue signaling. Tumor suppressor hypersensitivity was demonstrated by the reintroduction of the wild-type form of tumor suppressor genes and hereby stabilizing the wild-type protein or converting the mutant-form of the protein to a functioning protein. These studies showed the hypersensitivity of cancer cells to proteins expressed by tumor suppressor genes, leading to inhibited tumor progression [91]. One striking example has been the reactivation of $\mathrm{p} 53$, a tumor suppressor protein that regulates the cell cycle, in mouse tumor models leading to inactivation of cancer cells [97]. The concept of oncogene addiction has been further supported by the clinical success of specific inhibitors including tyrosine kinase inhibitors, such as imatinib, for treating CML, gefitinib or erlotinib for treating non-small cell lung cancer (NSCLC) with activating mutation of EFGR and latapinib for treating breast cancer with amplified HER2 expression [6].

Many tumor cell lines appear to have retained the same dependency on an activated oncogene as the tumor they were derived from. The cells in the cell line undergo proliferative arrest, senescence, differentiation or apoptosis upon inactivation of the signal that drives tumorigenesis. The same addictions observed in cell lines suggests that the cancer cells within a tumor will autonomously respond to acute oncoprotein inactivation, which is independent of external factors. In addition, since the oncogene addiction is maintained in the cell line, the trait must be beneficial or even essential for tumor cells. Surprisingly, in normal cells, inactivation of the very same genes to which tumor cells are addicted does not lead to obvious induction of proliferative arrest, senescence, differentiation or apoptosis. Thus, in cancer, addiction has evolved as a unique state that truly renders the tumor cells dependent on uninterrupted activity of the associated pathway. An implication of this difference in addiction between normal cells and tumor cells is that when the associated path ways involved are blocked, detrimental effects on the proliferation of cancer cells are expected while at the same time normal cells remain relatively unaffected. This difference between tumor cells and normal cells is crucial for effective cancer treatment with acceptable toxicity [85]. Understanding the molecular details of oncogene addiction is crucial for the design of targeted to therapies that successfully prolong a patient's life and prevent escape from treatment.

\section{Models for oncogene addiction}

In an oncogene-addicted cancer cell, the oncogene responsible for the proliferation of the cell plays an important role in balancing survival and death signals [90]. Several models have been proposed in an attempt to provide a molecular framework for the phenomenon of oncogene addiction and an explanation for the observation that inactivation of an oncogene in cancer cells, in contrast to normal cells, leads to selective growth inhibition, differentiation and/or apoptosis $[\mathbf{8 8 , 9 1 ]}$.

\section{Synthetic lethality}

The concept of 'synthetic lethality' attempts to explain the observation that normal cells, in contrast to tumor cells, are relatively unaffected by targeting the same oncogene. Two genes are 'synthetically lethal', if a mutation in one of the genes is compatible with viability of the cell but mutations in both genes results in cell death [91]. When a cancer cell is dependent for its survival on a mutated oncogene, the concept of synthetic lethality predicts that there may be a synthetically lethal relationship between the mutated oncogene and other genes. Inactivation or alteration of these genes would kill the cancer cell and would leave cells without the mutated oncogene unaffected [91].

A striking example that supports the concept of synthetic lethality is observed in breast cancers that contain a deficiency in tumor suppressor genes breast cancer 1 (BRCA-1) and breast cancer 2 (BRCA-2). Tumors with defects in these genes are compromised with regard to their ability to repair double-stranded DNA breaks by homologous recombination. In this form of breast cancer, extreme sensitivity is observed to the inhibitors of poly(ADP-ribose) polymerase-1 (PARP-1) $[98,99]$. PARP-1 is an enzyme normally involved inrecovery of DNA damage and PARP-1 inhibitors are selectively lethal to tumor cells with minimal toxicity to normal cells. It has been hypothesized that the extreme dependency of some cancer cells to an oncogene is due to the loss of the function of another gene during their development, which normally performs the same function. In more general terms, extreme dependency of cancer cells on a specific oncogene reflects their decreased adaptability due to several inactivated genes [88].

To identify the genes whose inactivation can potentially lead to specific death of cancer cells, synthetic lethality screens can be effective. With this method, lethal interactions of some genes have been uncovered with known oncogenes, such as the KRAS gene. The genes that exhibit a lethal interaction with the KRAS gene include the sulfotransferase (ST3) gene, TANKbinding kinase 1 (TBK1) gene and the gene for polo-kinase 1 [100-102]. In addition, studies have shown that renal cell carcinoma cells that lack the tumor suppressor von HippelLindau protein (PVHL) show an extreme sensitivity to mTOR inhibitors (mammalian target of rapamycin) [103].

\section{Non-oncogene addiction}

In addition to synthetic lethality, another model has been proposed to understand different addictions of cancer cells. This concept of 'non-oncogene addiction' is based on the observation that the tumorigenic state depends on the activities of a wide variety of genes and pathways, many 


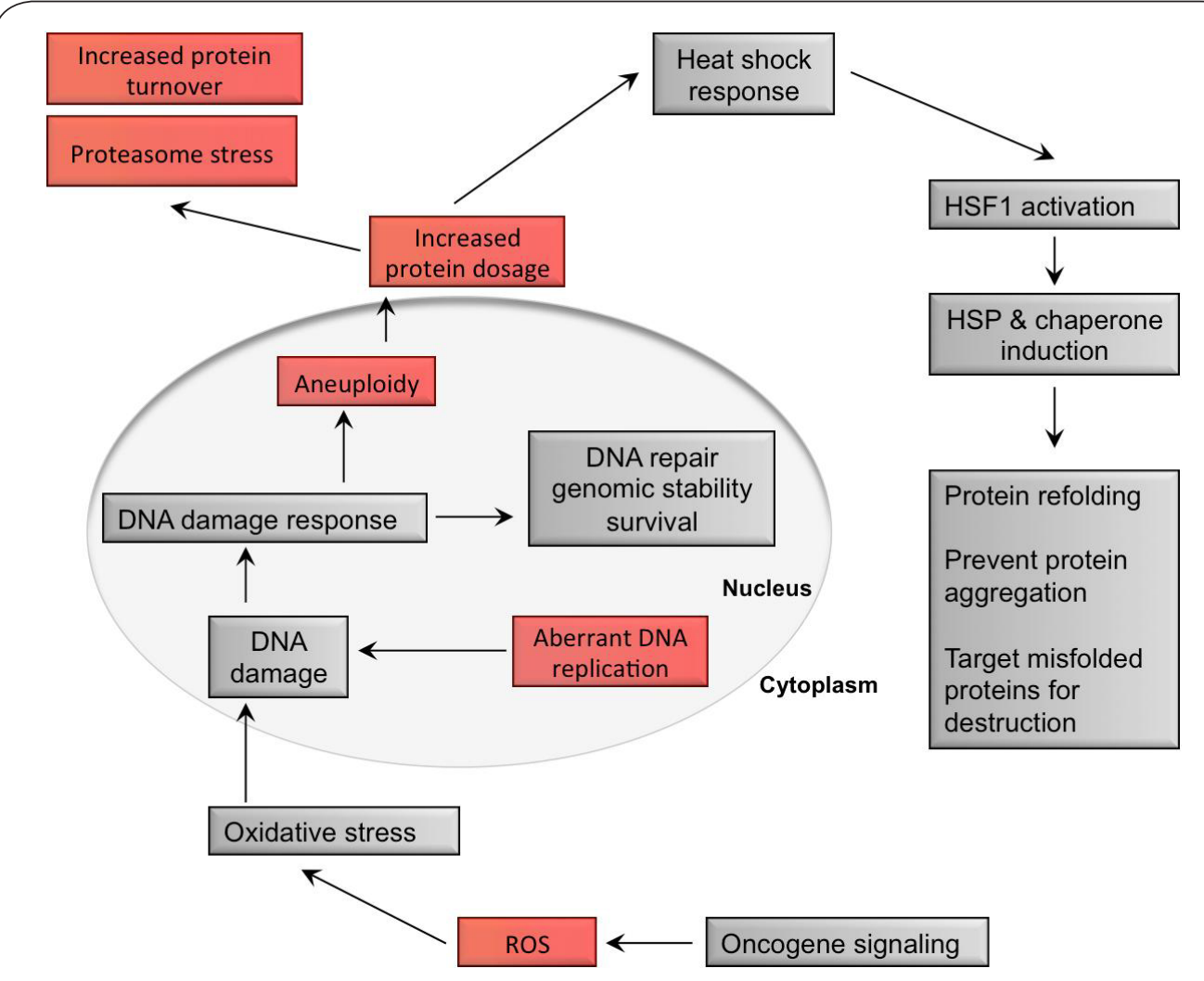

Figure 6. Non-oncogene addiction resulted from cellular stress pathway (over)activation in cancer cells. Cancer cells contain a non-oncogene addiction to certain cellular stress pathways. Oxidative damage, DNA damage and heat-shock is prevented by (over)expressing the appropriate signals for the stress-response. Heat-shock is prevented by HSF1 activation, resulting in the transcriptions of heat-shock proteins (HSPs) and other chaperones enabling the cancer cells to function with an increased protein dosage. In addition, the higher levels of reactive oxygen species (ROS) and aberrant DNA replication lead to DNA alterations and DNA-damage responses enable cell survival. (as has been described previously [104])

of which are not inherently oncogenic themselves [104]. The products of these genes are essential to support the tumorigenic state of the cancer cells and are not as important in normal cells. In tumors, genes involved in non-oncogenic addiction typically do not undergo mutations or significant genomic alterations.

Non-oncogene addiction has been observed by the dependency of cancer cells upon general stress responses, such as responses against oxidative stress, metabolic stress and heat shock, see (Figure 6) [90]. By activating these pathways, tumor cells can survive chromosomal changes more easily than normal cells, as cell death is not triggered [8]. The heatshock factor 1 (HSF1) protein is a transcription factor that is activated by a variety of cellular stresses that involve proteindenaturing risks, including heat and reduced oxygen content (hypoxia). HSF1 controls the expression of several heat-shock proteins (HSP) and other chaperones that promote protein refolding, prevent protein aggregation and target misfolded proteins for destruction. Hereby, HSF1 prevents death of the 'stressed' cell [104].

Cancer cells exhibit an increased protein dosage due to aneuploidy, proteasome stress, competition among proteins for access to chaperones and increased protein turnover. Therefore, the up-regulation of the heat-shock response in these cells can decrease the negative effects that result from the increased protein dosage. In addition to increased levels of proteins, increased levels of ROS and deregulated DNA replication in cancer cells lead to DNA damage and potentially threaten the viability of the cells. Hence, stress pathways are crucial for DNA-damage responses to provide genetic stability required for cell survival. Other stresses in cancer cells include metabolic and energy stress, end plasmatic reticulum stress, mitochondrial stress and membrane stress [104].

Non-oncogene addiction reflects the tumor's dependency on particular genes and pathways and provides important drug targets that, upon inhibition, will constitute synthetic 
Logtenberg et al. Oncology Discovery 2013,

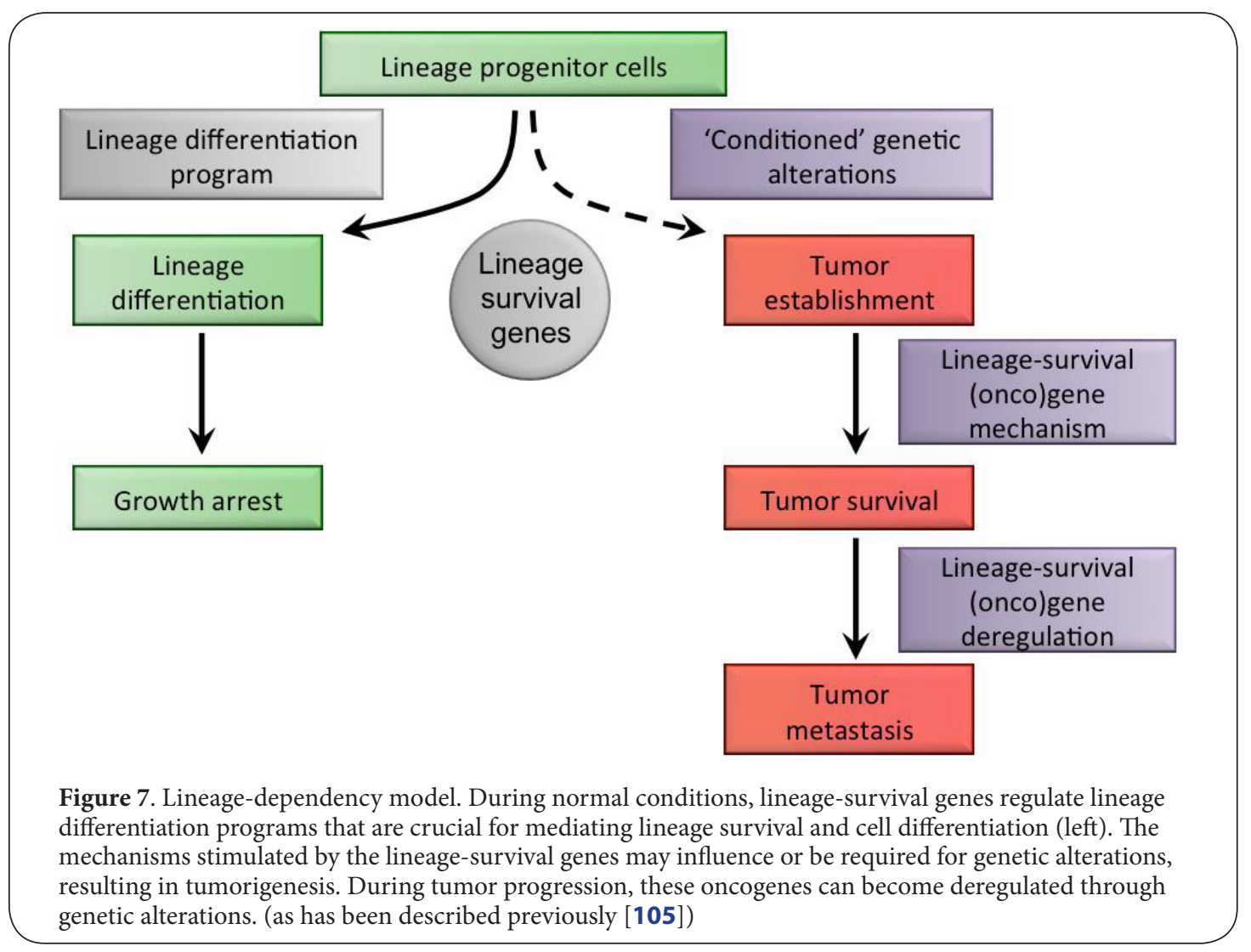

lethality with the tumor genotype [84].

\section{Lineage addiction}

The model of oncogene addiction inspired a related hypothesis, known as 'lineage addiction'. This model seeks to explain the involvement of deregulated specific lineage-pathways in the progress of tumor formation[105]. The oncogene-addiction theory describes the activation of cellular signals in tumor cells, which are absent in normal tissue, that elicit aberrant proliferative and anti-apoptotic effects. Tumor cells become exclusively dependent on these effects. In contrast, the lineageaddiction theory does not necessarily involve the acquisition of a new and tumor-specific function. Rather, it suggests that the persistence and deregulation of already existing survival mechanisms operating during normal lineage development result in tumorigenesis.

During normal development, master regulatory genes have crucial roles in tissue or organ progenitor cells by mediating lineage survival and cell differentiation. Tumors may rely on, or be addicted to these proliferation and survival programs. The programs influence or condition the range of tumor genetic alterations, while also exerting their own oncogenic functions. For example, in acute promyelocytic leukemia (APL), the neoplastic cells are aberrantly blocked in the promyelocytic stage of myeloid differentiation as a result of a translocation of the retinoic acid receptor a(RARA) gene [106]. Treatment of patients with all-trans retinoic acid (ATRA), a derivative of vitamin $A$, restores a normal myeloid differentiation program by displacing the retinoic acid receptor a fusion oncoprotein that drives APL carcinogenesis [107]. Thus, ATRA does not directly kill the tumor cells but induces their terminal differentiation, after which they go into spontaneous apoptosis.

During tumor progression, lineage-survival oncogenes can become deregulated through mutations, see (Figure 7). Many tumors might rely crucially on hallmark proliferation or survival programs that are embedded through the development of normal lineage precursor cells [105].

Further insights in the lineage-dependency hypothesis have been obtained from studies of collections of cell lines representing different cell lineages. High-resolution genomic maps showed chromosomal gains, losses and lossof-heterozygosis within cell lines [108]. Cell lines harboring lineage-restricted patterns of copy number alterations were used to examine whether the genetic events contained lineage-specific cancer genes. This approach resulted in the discovery of the role of the microphthalmia-associated transcription factor (MITF) gene in melanomas.

In normal melanocyte development, the MITF transcription factor regulates the differentiation program of the cells, which is associated with growth arrest, as well as melanocyte lineage survival, which involves proliferative and anti-apoptotic mechanisms $[109,110]$. In primary tumors, the amplification 
Logtenberg et al. Oncology Discovery 2013,

http://www.hoajonline.com/journals/pdf/2052-6199-1-7.pdf

doi: 10.7243/2052-6199-1-7

Table 2. Models of oncogene addiction and examples.

\begin{tabular}{|c|c|c|c|c|c|c|c|c|c|}
\hline \multicolumn{2}{|c|}{ Oncogene addiction } & \multicolumn{2}{|c|}{$\begin{array}{l}\text { Tumor suppressor } \\
\text { hypersensitivity }\end{array}$} & \multicolumn{2}{|l|}{ Synthetic lethality } & \multicolumn{2}{|c|}{$\begin{array}{l}\text { Non-oncogene } \\
\text { addiction }\end{array}$} & \multicolumn{2}{|l|}{ Lineage addiction } \\
\hline Gene & Cancer & Gene & Cancer & Gene & Cancer & Gene & Cancer & Gene & Cancer \\
\hline$M Y C$ & $\begin{array}{l}\text { Skin papillomas, } \\
\text { lymphomas and } \\
\text { osteosarcomas }\end{array}$ & P53 & Multiple & $B R C A 1$ and $P A R P-1$ & Breast cancer & HSF1 & Multiple & $\begin{array}{l}\text { Results in blocked in } \\
\text { promyelocytic stage of } \\
\text { myeloid differentiation }\end{array}$ & $\begin{array}{l}\text { Acute } \\
\text { promyelocytic } \\
\text { leukemia }\end{array}$ \\
\hline $\begin{array}{l}\text { HRAS and } \\
B C R-A B L\end{array}$ & $\begin{array}{l}\text { Melanoma and leukemia } \\
\text { mouse models }\end{array}$ & -- & -- & $\begin{array}{l}K R A S \text { and } S T 3 \text {, } \\
T B K 1, P L K 1\end{array}$ & -- & -- & -- & MITF & Melanomas \\
\hline KRAS & Colorectal cancer & -- & -- & $P V H L$ and mTOR & $\begin{array}{l}\text { renal cell } \\
\text { carcinoma }\end{array}$ & -- & -- & -- & -- \\
\hline $\begin{array}{l}\text { Tyrosine } \\
\text { kinases }\end{array}$ & $\begin{array}{l}\text { Chronic myelogenous } \\
\text { leukemia }\end{array}$ & -- & -- & -- & -- & -- & -- & -- & -- \\
\hline$E F G R$ & Non-small cell lung cancer & -- & -- & -- & -- & -- & -- & -- & -- \\
\hline HER2 & Breast cancer & -- & -- & -- & -- & -- & -- & -- & -- \\
\hline
\end{tabular}

of the MITF gene is associated with metastatic disease and correlates with decreased overall patient survival [111]. Apparently, MITF confers cell cycle arrest in normal melanocytes and proliferation in melanomas in a context-dependent manner. The cancerous melanoma cells have uncoupled the pro-survival effects of MITF from its growth-inhibitory effects, and suggest a tumor lineage-specific melanoma dependency for MITF. When MITF is inhibited in melanoma cells, proliferation is terminated.

Overall, the discovery of the function of MITF in melanoma cells reveals a lineage-addiction of the cancer cell to the master survival functions that is required for relevant cellular lineage during development and differentiation [108]. Other genes that have been found to provoke lineage dependency have suggested that in general, lineage dependency genes appears to induce proliferation in the tumor cells from a cell lineage, but differentiation in the normal cells. The majority of lineage dependency genes correspond to lineage restricted transcription factors [91]. In Table 2 the different models of oncogene addiction and examples that have been discussed are summarized.

\section{Hallmarks of cancer and therapies}

In this review, some important interrelated themes concerning the progression and evolution of cancer have been discussed. Tumors result from clonal expansion of cells with driver mutations and often result in the acquisition of the hallmarks of cancer [112]. Cancer cells may exploit complex molecular networks that result in hypersensitivities or addiction to the expression of oncogenes or deletion of tumor suppressor genes. When cancer cells develop such dependencies, targeting these genes may provide a basis for the development of therapies. For example, small molecule drug imatinib has been developed to target BCR/ABL tyrosine kinase in CML. Other tyrosine kinase inhibitors like gefitinib and erlotinib specifically target epidermal growth factor receptor (EGFR) tyrosine kinase domains in non-small cell lung carcinoma [113].

Long-term beneficial effects of these drugs are limited because often, mutations of the targeted proteins occur. The long-term effect of imatinib can be altered due to mutations occurring at gatekeeper residues of the kinase domains. These mutations result in the inability of imatinib to bind to its target site and consequently lead to resistance of the cells [113]. Cancer cells can also avoid the effects of drugs by amplification of other oncogenes or inactivation of alternative survival pathways [113]. In addition, the evasion of apoptotic pathways by mutations that inactive genes that normally code for apoptotic proteins, such as p53, or activating mutations in genes that code for anti-apoptotic proteins, such as BCL-2, can also result in resistance [113]. Besides oncogene addiction and hypersensitivies, stem-cell like properties of a small subset of cancer cells also help tumors to become resistant to anticancer agents [112].

CSCs are thought to survive drug-induced selection pressures, ultimately leading to subpopulations that contribute to cancer relapse [113]. Patients with the 'same' cancer often respond differently to the same treatment, based on the extensive variation in the different genes that are mutated, the nature of these mutations and their consequences for the behavior of the cancer cells. Furthermore, the heterogeneous character of the cancer that develops due to clonal evolution of tumor cell also explains why similar cancers respond differently to therapeutic treatments [112]. Small subpopulations of cells may acquire or already possess features that enable them to survive during selective pressures provided by drugs [113]. Molecular profiling of cancers and further understanding of the basis of tumor heterogeneity will be instrumental identifying patient subpopulations. This stratification is an important step towards reaching the ambitious goal 'personalized medicine' and eventually a cure for cancer.

\section{Conclusion}

Adult stem cells are present in every organism. The zoned model proposes that in adult tissues, two populations of adult stem cells exist: one responsible for self-renewal and the other responsible for asymmetric cell division to account 
Logtenberg et al. Oncology Discovery 2013,

for daily regeneration tasks. Tumor heterogeneity is a known phenomenon in cancer research and arises due to a clonal evolution process among tumor cells. Cancer cells that contain driver mutations are thought to drive and sustain tumor growth at the expense of other, less adapted tumor cells. Specific pathways that alter certain cell functions are activated with these driver mutations. To understand the mechanisms that drive the heterogeneity of tumors, the cancer stem cell hypothesis has emerged. This theory suggests that a small subset of specialized stem-cell like cells sustains the tumor and gives rise to more differentiated tumor cell types. These CSCs may arise from normal stem cells, progenitor cells or even from fully mature cell types. CSCs are possibly generated bya switch from an epithelial cell type to a mesenchymal cell type by the process of EMT. This increases stem cell properties in the cell and has also been proposed to enable metastases. Furthermore, the altered relationship some tumor cells have to certain internal signaling pathways has been described as 'oncogene addiction'. Cells may have different mutations and dependencies on different pathways for their survival or metastatic potential. Different models attempted to explain the complex and different dependencies of cancer cells have emerged, including synthetic lethality, non-oncogene addiction and lineage addiction.

The concept of oncogene addiction has been supported by positive clinical results of inhibitors targeted to specific pathways in tumor cells. Understanding central themescontributing to the formation and progression of cancer is crucial for the development of more effective therapies. Identifying certain populations of cancer cells with different roles in the tumor or different internal, distinct, dependencies may increase the understanding of invasive cells or cells that are resistant to specific therapies. The combined knowledge of oncogene addiction and CSCs helps to identify new drugs for improved cancer treatments. Identifying possible oncogenic addictions or other dependencies in CSCs may result in targeted therapy with minimum toxicity to surrounding cells. With a clearer outline of how cancer cells specifically operate and interact in tumors and metastases, improved and more targeted mechanism can be envisioned that possibly contributes to the war against this devastating disease.

\section{List of abbreviations}

$A B L$ : Abelson murine leukemia viral oncogene homolog 1 AML: acute myeloid leukemia

ALD-1: agd2-like defense response protein 1

APC: adenomatous polyposis coli

APL: acute promyelocytic leukemia

ATRA: all-trans retinoic acid

BCL-2: B cell lymphoma 2

BCR: breakpoint cluster region

BMP: bone morphogenetic protein

BMI-1: B lymphoma Mo-MLV insertion region 1

BRCA1: breast cancer type 1

BRCA2: breast cancer type 2

CML: chronic myelogenous leukemia
CSC: cancer stem cell

CTC: circulating tumor cell

EGFR: epidermal growth factor receptor

EMT: epithelial-mesenchymal transition

EPCAM: epithelial cell adhesion molecule

FoxC2: forkhead box protein C2

HER2: human epidermal growth factor receptor 2

HRAS: Harvey rat sarcoma virus oncogene

HSF1: heat-shock factor 1

HSP: heat-shock protein

KLF4: Krueppel-like factor 4

KRAS: V-Ki-ras2 Kirsten rat sarcoma viral oncogene homol

MAPK: mitogen-activated protein kinases

MET: mesenchymal-epithelial transition

miR-124: microRNA-124

MITF: microphthalmia-associated transcription factor

MMP-2: metalloproteinase-2

MMP-9: metalloproteinase-9

MYC: myelocytomatosis

NFKB: nuclear factor kappa-light-chain-

enhancer of activated B cells

NSCLC: non-small cell lung cancer

Oct-4: octamer-binding transcription factor 4

PARP-1: poly(ADP-ribose) polymerase-1

PI3k: phosphatidylinositide 3-kinases

PTEN: phosphatase and tensin homolog

PVHL: von Hippel-Lindau tumor suppressor protein

RARA: retinoic acid receptor a

RAS: rat sarcoma

ROS: reactive oxygen species

ST3: sulfotransferase

STAT: signal transducer and activator of transcription

TBK1: TANK-binding kinase 1

TGF- $\beta$ : transforming growth factor beta

Competing interests

The authors declare that they have no competing interests.

Authors' contributions

\begin{tabular}{|l|c|c|}
\hline Authors' contributions & MEWL & JB \\
\hline Research concept and design & -- & -- \\
\hline Collection and/or assembly of data & $\checkmark$ & -- \\
\hline Data analysis and interpretation & $\checkmark$ & $\checkmark$ \\
\hline Writing the article & $\checkmark$ & \\
\hline Critical revision of the article & -- & $\checkmark$ \\
\hline Final approval of article & -- & $\checkmark$ \\
\hline Statistical analysis & -- & -- \\
\hline
\end{tabular}

\section{Acknowledgement}

We thank Dr. Fred Wiegant for his interest and contributions to this manuscript.

\section{Publication history}

Editors: Ashish Saxena, University of Texas, USA. Jim Song, Penn State University College of Medicine, USA. EICs: Paul J. Higgins, Albany Medical College, USA. GJ Peters, VU University Medical Center, Netherlands. William Chi-shing Cho, Queen Elizabeth Hospital, Hong Kong. Received: 05-Jul-2013 Revised: 05-Sep-2013

Re-revised: 16-Aug-2013 Final-Re-revised: 18-Aug-2013

Accepted: 02-Oct-2013 Published: 05-Nov-2013 
Logtenberg et al. Oncology Discovery 2013,

\section{References}

1. Greaves M and Maley CC. Clonal evolution in cancer. Nature. 2012; 481:306-13. | Article | PubMed Abstract | PubMed Full Text

2. Gough NR. Focus issue: From genomic mutations to oncogenic pathways. Sci Signal. 2013; 6:eg3. | Article | PubMed

3. Dick JE. Stem cell concepts renew cancer research. Blood. 2008; 112:4793-807. | Article | PubMed

4. Shiozawa Y, Nie B, Pienta KJ, Morgan TM and Taichman RS. Cancer stem cells and their role in metastasis. Pharmacol Ther. 2013; 138:285-93. | Article I PubMed

5. Welte $Y$, Adjaye J, Lehrach HR and Regenbrecht CR. Cancer stem cells in solid tumors: elusive or illusive? Cell Commun Signal. 2010; 8:6. | Article | PubMed Abstract | PubMed Full Text

6. Bean GR, Ganesan YT, Dong Y, Takeda S, Liu H, Chan PM, Huang $Y$, Chodosh LA, Zambetti GP, Hsieh JJ and Cheng EH. PUMA and BIM are required for oncogene inactivation-induced apoptosis. Sci Signal. 2013; 6:ra20:doi: 10.1126/scisignal.2003483. | Article | PubMed Abstract | PubMed Full Text

7. Nowell PC. The clonal evolution of tumor cell populations. Science. 1976; 194:23-8. | Article | PubMed

8. Vogelstein B, Papadopoulos N, Velculescu VE, Zhou S, Diaz LA, Jr. and Kinzler KW. Cancer genome landscapes. Science. 2013; 339:1546-58. Article | PubMed Abstract | PubMed Full Text

9. Fearon ER and Vogelstein B. A genetic model for colorectal tumorigenesis. Cell. 1990; 61:759-67. | Article | PubMed

10. Colicelli J. Human RAS superfamily proteins and related GTPases. Sci STKE. 2004; 2004:RE13. | Article | PubMed Abstract | PubMed Full Text

11. Parsons DW, Jones S, Zhang X, Lin JC, Leary RJ, Angenendt P, Mankoo $\mathrm{P}$, Carter $\mathrm{H}$, Siu IM and Gallia GL et al. An integrated genomic analysis of human glioblastoma multiforme. Science. 2008; 321:1807-12:doi: 10.1126/science. | Article | PubMed Abstract | PubMed Full Text

12. Greaves M. Cancer stem cells as 'units of selection'. Evol Appl. 2013; 6:102-8. | Article | PubMed

13. Hanahan $D$ and Weinberg RA. Hallmarks of cancer: the next generation. Cell. 2011; 144:646-74. | Article | PubMed

14. van de Stolpe A. On the origin and destination of cancer stem cells: a conceptual evaluation. Am J Cancer Res. 2013; 3:107-16. | PubMed Abstract | PubMed Full Text

15. Visvader JE. Cells of origin in cancer. Nature. 2011; 469:314-22. | Article | PubMed

16. Rottenberg S, Vollebergh MA, de Hoon B, de Ronde J, Schouten PC, Kersbergen A, Zander SA, Pajic M, Jaspers JE and Jonkers $M$ et al. Impact of intertumoral heterogeneity on predicting chemotherapy response of BRCA1-deficient mammary tumors. Cancer Res. 2012; 72:2350-61. | Article | PubMed Abstract | PubMed Full Text

17. Williams SA, Anderson WC, Santaguida MT and Dylla SJ. Patient-derived xenografts, the cancer stem cell paradigm, and cancer pathobiology in the 21st century. Lab Invest. 2013; 93:970-82. | Article | PubMed

18. Baisse B, Bouzourene H, Saraga EP, Bosman FT and Benhattar J. Intratumor genetic heterogeneity in advanced human colorectal adenocarcinoma. Int J Cancer. 2001; 93:346-52. | Article | PubMed

19. Yachida S, Jones S, Bozic I, Antal T, Leary R, Fu B, Kamiyama M, Hruban RH, Eshleman JR and Nowak MA et al. Distant metastasis occurs late during the genetic evolution of pancreatic cancer. Nature. 2010; 467:1114-7. | Article | PubMed Abstract | PubMed Full Text

20. Campbell PJ, Yachida S, Mudie LJ, Stephens PJ, Pleasance ED, Stebbings LA, Morsberger LA, Latimer C, McLaren S and Lin ML et al. The patterns and dynamics of genomic instability in metastatic pancreatic cancer. Nature. 2010; 467:1109-13. | Article | PubMed Abstract | PubMed Full Text

21. Goasguen N, de Chaisemartin C, Brouquet A, Julie C, Prevost GP, Laurent-Puig $P$ and Penna C. Evidence of heterogeneity within colorectal liver metastases for allelic losses, mRNA level expression and in vitro response to chemotherapeutic agents. Int J Cancer. 2010; 127:1028-37. | Article | PubMed
22. Diaz LA, Jr., Williams RT, Wu J, Kinde I, Hecht JR, Berlin J, Allen B, Bozic I, Reiter JG, Nowak MA, Kinzler KW, Oliner KS and Vogelstein B. The molecular evolution of acquired resistance to targeted EGFR blockade in colorectal cancers. Nature. 2012; 486:537-40. | Article | PubMed Abstract | PubMed Full Text

23. Ljungman $M$ and Lane DP. Transcription - guarding the genome by sensing DNA damage. Nat Rev Cancer. 2004; 4:727-37. | Article | PubMed

24. Ljungman M. Dial 9-1-1 for p53: mechanisms of $p 53$ activation by cellular stress. Neoplasia. 2000; 2:208-25. | Pdf | PubMed Abstract PubMed Full Text

25. Youn $A$ and Simon R. Identifying cancer driver genes in tumor genome sequencing studies. Bioinformatics. 2011; 27:175-81. | Article | PubMed Abstract | PubMed Full Text

26. Perrimon N, Pitsouli $C$ and Shilo BZ. Signaling mechanisms controlling cell fate and embryonic patterning. Cold Spring Harb Perspect Biol. 2012; 4:a005975. | Article | PubMed

27. Chauhan VP, Stylianopoulos T, Boucher $Y$ and Jain RK. Delivery of molecular and nanoscale medicine to tumors: transport barriers and strategies. Annu Rev Chem Biomol Eng. 2011; 2:281-98. | Article | PubMed

28. Hynes NE and MacDonald G. ErbB receptors and signaling pathways in cancer. Curr Opin Cell Biol. 2009; 21:177-84. | Article I PubMed

29. Wang $\mathrm{CH}, \mathrm{Wu} \mathrm{SB}, \mathrm{Wu} \mathrm{YT}$ and Wei YH. Oxidative stress response elicited by mitochondrial dysfunction: implication in the pathophysiology of aging. Exp Biol Med (Maywood). 2013; 238:45060. | Article | PubMed

30. Verbon $\mathrm{EH}$, Post JA and Boonstra J. The influence of reactive oxygen species on cell cycle progression in mammalian cells. Gene. 2012; 511:1-6. | Article | PubMed

31. Stracker TH, Roig I, Knobel PA and Marjanovic M. The ATM signaling network in development and disease. Front Genet. 2013; 4:37. | Article | PubMed Abstract | PubMed Full Text

32. Suva $M L$, Riggi $N$ and Bernstein $B E$. Epigenetic reprogramming in cancer. Science. 2013; 339:1567-70. | Article | PubMed

33. Nguyen LV, Vanner R, Dirks $P$ and Eaves $\mathrm{CJ}$. Cancer stem cells: an evolving concept. Nat Rev Cancer. 2012; 12:133-43. | Article | PubMed

34. $\mathrm{Li} \mathrm{L}$ and Clevers $\mathrm{H}$. Coexistence of quiescent and active adult stem cells in mammals. Science. 2010; 327:542-5. | Article | PubMed

35. Orford KW and Scadden DT. Deconstructing stem cell self-renewal: genetic insights into cell-cycle regulation. Nat Rev Genet. 2008; 9:11528. | Article | PubMed

36. Leushacke $M$ and Barker N. Lgr5 and Lgr6 as markers to study adult stem cell roles in self-renewal and cancer. Oncogene. 2012; 31:300922. | Article | PubMed

37. Ablett MP, Singh JK and Clarke RB. Stem cells in breast tumours: are they ready for the clinic? Eur J Cancer. 2012; 48:2104-16. | Article | PubMed

38. Clarke MF, Dick JE, Dirks PB, Eaves $\mathrm{CJ}$, Jamieson $\mathrm{CH}$, Jones $\mathrm{DL}$, Visvader J, Weissman IL and Wahl GM. Cancer stem cells--perspectives on current status and future directions: AACR Workshop on cancer stem cells. Cancer Res. 2006; 66:9339-44. | Article | PubMed

39. Valent P, Bonnet D, De Maria R, Lapidot T, Copland M, Melo JV, Chomienne C, Ishikawa F, Schuringa JJ and Stassi G et al. Cancer stem cell definitions and terminology: the devil is in the details. Nat Rev Cancer. 2012; 12:767-75. | Article | PubMed

40. Sullivan JP, Minna JD and Shay JW. Evidence for self-renewing lung cancer stem cells and their implications in tumor initiation, progression, and targeted therapy. Cancer Metastasis Rev. 2010; 29:61-72. | Article | PubMed Abstract | PubMed Full Text

41. Bonnet $D$ and Dick JE. Human acute myeloid leukemia is organized as a hierarchy that originates from a primitive hematopoietic cell. Nat Med. 1997; 3:730-7. | Article | PubMed

42. Sabbath KD, Ball ED, Larcom P, Davis RB and Griffin JD. Heterogeneity of clonogenic cells in acute myeloblastic leukemia. J Clin Invest. 1985; 
Logtenberg et al. Oncology Discovery 2013,

75:746-53. | Article | PubMed Abstract | PubMed Full Text

43. Griffin JD and Lowenberg B. Clonogenic cells in acute myeloblastic leukemia. Blood. 1986; 68:1185-95. | Article | PubMed

44. van Vlerken LE, Hurt EM and Hollingsworth RE. The role of epigenetic regulation in stem cell and cancer biology. J Mol Med (Berl). 2012; 90:791-801. | Article | PubMed

45. Reya $\mathrm{T}$ and Clevers $\mathrm{H}$. Wnt signalling in stem cells and cancer. Nature. 2005; 434:843-50. | Article | PubMed

46. Dave B, Mittal V, Tan NM and Chang JC. Epithelial-mesenchymal transition, cancer stem cells and treatment resistance. Breast Cancer Res. 2012; 14:202. | Article | PubMed Abstract | PubMed Full Text

47. Tiwari N, Gheldof A, Tatari M and Christofori G. EMT as the ultimate survival mechanism of cancer cells. Semin Cancer Biol. 2012; 22:194207. | Article | PubMed

48. Kalluri $R$ and Weinberg RA. The basics of epithelial-mesenchymal transition. J Clin Invest. 2009; 119:1420-8. | Article | PubMed Abstract | PubMed Full Text

49. Thiery JP, Acloque H, Huang RY and Nieto MA. Epithelial-mesenchymal transitions in development and disease. Cell. 2009; 139:871-90. | Article | PubMed

50. Scheel C, Eaton EN, Li SH, Chaffer CL, Reinhardt F, Kah KJ, Bell G, Guo W, Rubin J, Richardson AL and Weinberg RA. Paracrine and autocrine signals induce and maintain mesenchymal and stem cell states in the breast. Cell. 2011; 145:926-40. | Article | PubMed

51. Tse JC and Kalluri R. Mechanisms of metastasis: epithelialto-mesenchymal transition and contribution of tumor microenvironment. J Cell Biochem. 2007; 101:816-29. | Article | PubMed

52. Li Y and Laterra J. Cancer stem cells: distinct entities or dynamically regulated phenotypes? Cancer Res. 2012; 72:576-80. | Article | PubMed Abstract | PubMed Full Text

53. Clevers $\mathrm{H}$ and Nusse R. Wnt/ß-Catening Signaling and Disease. Cell. 2012; 149:1192-205. | Article

54. Klarmann GJ, Decker A and Farrar WL. Epigenetic gene silencing in the Wnt pathway in breast cancer. Epigenetics. 2008; 3:59-63. | PubMed

55. Korkaya $\mathrm{H}$, Liu S and Wicha MS. Breast cancer stem cells, cytokine networks, and the tumor microenvironment. J Clin Invest. 2011; 121:3804-9. | Article | PubMed Abstract | PubMed Full Text

56. Visvader JE and Lindeman GJ. Cancer stem cells in solid tumours: accumulating evidence and unresolved questions. Nat Rev Cancer. 2008; 8:755-68. | Article | PubMed

57. Rubin LL and de Sauvage FJ. Targeting the Hedgehog pathway in cancer. Nat Rev Drug Discov. 2006; 5:1026-33. | Article | PubMed

58. Jiang L, Li J and Song L. Bmi-1, stem cells and cancer. Acta Biochim Biophys Sin (Shanghai). 2009; 41:527-34. | Article | PubMed

59. Ikushima H, Todo T, Ino Y, Takahashi M, Miyazawa $\mathrm{K}$ and Miyazono K. Autocrine TGF-beta signaling maintains tumorigenicity of gliomainitiating cells through Sry-related HMG-box factors. Cell Stem Cell. 2009; 5:504-14. | Article | PubMed

60. Charles N, Ozawa T, Squatrito M, Bleau AM, Brennan CW, Hambardzumyan D and Holland EC. Perivascular nitric oxide activates notch signaling and promotes stem-like character in PDGF-induced glioma cells. Cell Stem Cell. 2010; 6:141-52. | Article | PubMed

61. Wang Z, Li Y, Banerjee $S$ and Sarkar FH. Emerging role of Notch in stem cells and cancer. Cancer Lett. 2009; 279:8-12. | Article | PubMed Abstract I PubMed Full Text

62. Yu H, Mouw JK and Weaver VM. Forcing form and function: biomechanical regulation of tumor evolution. Trends Cell Biol. 2011; 21:47-56. | Article | PubMed Abstract | PubMed Full Text

63. Baccelli I and Trumpp A. The evolving concept of cancer and metastasis stem cells. J Cell Biol. 2012; 198:281-93. | Article | PubMed Abstract | PubMed Full Text

64. Liu H, Patel MR, Prescher JA, Patsialou A, Qian D, Lin J, Wen S, Chang $\mathrm{YF}, \mathrm{Bachmann} \mathrm{MH}$ and Shimono $\mathrm{Y}$ et al. Cancer stem cells from human breast tumors are involved in spontaneous metastases in orthotopic mouse models. Proc Natl Acad Sci U S A. 2010; 107:18115-20. | Article | PubMed Abstract | PubMed Full Text

65. Li F, Tiede B, Massague J and Kang Y. Beyond tumorigenesis: cancer stem cells in metastasis. Cell Res. 2007; 17:3-14. | Article I PubMed

66. Wang X, Zhu Y, Ma Y, Wang J, Zhang F, Xia $Q$ and Fu D. The role of cancer stem cells in cancer metastasis: new perspective and progress. Cancer Epidemiol. 2013; 37:60-3. | Article | PubMed

67. Morel AP, Lievre M, Thomas C, Hinkal G, Ansieau S and Puisieux A. Generation of breast cancer stem cells through epithelialmesenchymal transition. PLoS One. 2008; 3:e2888. | Article | PubMed Abstract | PubMed Full Text

68. Karnoub AE, Dash AB, Vo AP, Sullivan A, Brooks MW, Bell GW, Richardson AL, Polyak K, Tubo R and Weinberg RA. Mesenchymal stem cells within tumour stroma promote breast cancer metastasis. Nature. 2007; 449:557-63. | Article | PubMed

69. Aktas B, Tewes M, Fehm T, Hauch S, Kimmig R and Kasimir-Bauer $S$. Stem cell and epithelial-mesenchymal transition markers are frequently overexpressed in circulating tumor cells of metastatic breast cancer patients. Breast Cancer Res. 2009; 11:R46. | Article | PubMed Abstract | PubMed Full Text

70. Martin FT, Dwyer RM, Kelly J, Khan S, Murphy JM, Curran C, Miller N, Hennessy E, Dockery P and Barry FP et al. Potential role of mesenchymal stem cells (MSCs) in the breast tumour microenvironment: stimulation of epithelial to mesenchymal transition (EMT). Breast Cancer Res Treat. 2010; 124:317-26. | Article | PubMed

71. Kuo TC, Chen CT, Baron D, Onder TT, Loewer S, Almeida S, Weismann CM, Xu P, Houghton JM, Gao FB, Daley GQ and Doxsey S. Midbody accumulation through evasion of autophagy contributes to cellular reprogramming and tumorigenicity. Nat Cell Biol. 2011; 13:1214-23. | Article I PubMed

72. Yu F, Li J, Chen H, Fu J, Ray S, Huang S, Zheng H and Ai W. Kruppel-like factor 4 (KLF4) is required for maintenance of breast cancer stem cells and for cell migration and invasion. Oncogene. 2011; 30:2161-72. | Article | PubMed Abstract | PubMed Full Text

73. Zhou J, Wulfkuhle J, Zhang H, Gu P, Yang Y, Deng J, Margolick JB, Liotta LA, Petricoin E, 3rd and Zhang Y. Activation of the PTEN/mTOR/STAT3 pathway in breast cancer stem-like cells is required for viability and maintenance. Proc Natl Acad Sci U S A. 2007; 104:16158-63. | Article | PubMed Abstract | PubMed Full Text

74. Mulholland DJ, Kobayashi N, Ruscetti M, Zhi A, Tran LM, Huang J, Gleave $\mathrm{M}$ and Wu H. Pten loss and RAS/MAPK activation cooperate to promote EMT and metastasis initiated from prostate cancer stem/ progenitor cells. Cancer Res. 2012; 72:1878-89. | Article | PubMed Abstract | PubMed Full Text

75. Hoffman BD, Grashoff C and Schwartz MA. Dynamic molecular processes mediate cellular mechanotransduction. Nature. 2011; 475:316-23. | Article | PubMed

76. Hou JM, Krebs M, Ward T, Sloane R, Priest L, Hughes A, Clack G, Ranson $\mathrm{M}$, Blackhall $\mathrm{F}$ and Dive $\mathrm{C}$. Circulating tumor cells as a window on metastasis biology in lung cancer. Am J Pathol. 2011; 178:989-96. Article | PubMed Abstract I PubMed Full Text

77. Ma J, Lin JY, Alloo A, Wilson BJ, Schatton T, Zhan Q, Murphy GF, Waaga-Gasser AM, Gasser M, Stephen Hodi F, Frank NY and Frank MH. Isolation of tumorigenic circulating melanoma cells. Biochem Biophys Res Commun. 2010; 402:711-7. | Article | PubMed Abstract | PubMed Full Text

78. Takahashi K, Okita K, Nakagawa M and Yamanaka S: Induction of pluripotent stem cells from fibroblast cultures. Nat Protoc 2006, 2:3081-9. | Article | PubMed Abstract | PubMed Full Text

79. Kurose K, Gilley K, Matsumoto S, Watson PH, Zhou XP and Eng C. Frequent somatic mutations in PTEN and TP53 are mutually exclusive in the stroma of breast carcinomas. Nat Genet. 2002; 32:355-7. I Article | PubMed

80. van Nes JG, de Kruijf EM, Putter H, Faratian D, Munro A, Campbell F, Smit VT, Liefers GJ, Kuppen PJ, van de Velde CJ and Bartlett JM. Co- 
Logtenberg et al. Oncology Discovery 2013,

expression of SNAIL and TWIST determines prognosis in estrogen receptor-positive early breast cancer patients. Breast Cancer Res Treat. 2012; 133:49-59. | Article | PubMed

81. Kirschmann DA, Seftor EA, Hardy KM, Seftor RE and Hendrix MJ. Molecular pathways: vasculogenic mimicry in tumor cells: diagnostic and therapeutic implications. Clin Cancer Res. 2012; 18:2726-32. | Article | PubMed Abstract | PubMed Full Text

82. van de Stolpe A, Pantel K, Sleijfer S, Terstappen LW and den Toonder JM. Circulating tumor cell isolation and diagnostics: toward routine clinical use. Cancer Res. 2011; 71:5955-60. | Article | PubMed

83. Haylock DN and Nilsson SK. Stem cell regulation by the hematopoietic stem cell niche. Cell Cycle. 2005; 4:1353-5. I Article I PubMed

84. Luo J, Solimini NL and Elledge SJ. Principles of cancer therapy: oncogene and non-oncogene addiction. Cell. 2009; 136:823-37. | Article I PubMed Abstract I PubMed Full Text

85. Sharma SV and Settleman J. Oncogene addiction: setting the stage for molecularly targeted cancer therapy. Genes Dev. 2007; 21:3214-31. | Article | PubMed

86. Weinstein IB. Disorders in cell circuitry during multistage carcinogenesis: the role of homeostasis. Carcinogenesis. 2000; 21:85764. | Article | PubMed

87. Weinstein IB. Cancer. Addiction to oncogenes--the Achilles heal of cancer. Science. 2002; 297:63-4. | Article | PubMed

88. Weinstein IB and Joe AK. Mechanisms of disease: Oncogene addiction-a rationale for molecular targeting in cancer therapy. Nat Clin Pract Oncol. 2006; 3:448-57. | Article | PubMed

89. Weinstein IB and Joe A. Oncogene addiction. Cancer Res. 2008; 68:3077-80; discussion 3080. | Article | PubMed

90. Roulston A, Muller WJ and Shore GC. BIM, PUMA, and the achilles' heel of oncogene addiction. Sci Signal. 2013; 6:pe12. | Article | PubMed

91. Sharma SV and Settleman J. Exploiting the balance between life and death: targeted cancer therapy and "oncogenic shock". Biochem Pharmacol. 2010; 80:666-73. | Article | PubMed

92. Felsher DW and Bishop JM. Reversible tumorigenesis by MYC in hematopoietic lineages. Mol Cell. 1999; 4:199-207. I Article I PubMed

93. Jain M, Arvanitis C, Chu K, Dewey W, Leonhardt E, Trinh M, Sundberg CD, Bishop JM and Felsher DW. Sustained loss of a neoplastic phenotype by brief inactivation of MYC. Science. 2002; 297:102-4. Article | PubMed

94. Huettner CS, Zhang P, Van Etten RA and Tenen DG. Reversibility of acute B-cell leukaemia induced by BCR-ABL1. Nat Genet. 2000; 24:5760. I Article I PubMed

95. Chin L, Tam A, Pomerantz J, Wong M, Holash J, Bardeesy N, Shen Q, O'Hagan R, Pantginis J, Zhou H, Horner JW, 2nd, Cordon-Cardo C, Yancopoulos GD and DePinho RA. Essential role for oncogenic Ras in tumour maintenance. Nature. 1999; 400:468-72. I Article I PubMed

96. Shirasawa S, Furuse M, Yokoyama N and Sasazuki T. Altered growth of human colon cancer cell lines disrupted at activated Ki-ras. Science. 1993; 260:85-8. | Article | PubMed

97. Martins $C P$, Brown-Swigart $L$ and Evan GI. Modeling the therapeutic efficacy of p53 restoration in tumors. Cell. 2006; 127:1323-34. | Article I PubMed

98. Bryant HE, Schultz N, Thomas HD, Parker KM, Flower D, Lopez E, Kyle S, Meuth M, Curtin NJ and Helleday T. Specific killing of BRCA2-deficient tumours with inhibitors of poly(ADP-ribose) polymerase. Nature. 2005; 434:913-7. | Article | PubMed

99. Farmer H, McCabe N, Lord CJ, Tutt AN, Johnson DA, Richardson TB, Santarosa M, Dillon KJ, Hickson I, Knights C, Martin NM, Jackson SP, Smith GC and Ashworth A. Targeting the DNA repair defect in BRCA mutant cells as a therapeutic strategy. Nature. 2005; 434:917-21. | Article | PubMed

100. Barbie DA, Tamayo P, Boehm JS, Kim SY, Moody SE, Dunn IF, Schinzel AC, Sandy P, Meylan E and Scholl C et al. Systematic RNA interference reveals that oncogenic KRAS-driven cancers require TBK1. Nature. 2009; 462:108-12. | Article | PubMed Abstract | PubMed Full Text
101. Scholl C, Frohling S, Dunn IF, Schinzel AC, Barbie DA, Kim SY, Silver SJ, Tamayo P, Wadlow RC, Ramaswamy S, Dohner K, Bullinger L, Sandy P, Boehm JS, Root DE, Jacks T, Hahn WC and Gilliland DG. Synthetic lethal interaction between oncogenic KRAS dependency and STK33 suppression in human cancer cells. Cell. 2009; 137:821-34. | Article | PubMed

102. Luo J, Emanuele MJ, Li D, Creighton CJ, Schlabach MR, Westbrook TF, Wong KK and Elledge SJ. A genome-wide RNAi screen identifies multiple synthetic lethal interactions with the Ras oncogene. Cell. 2009; 137:835-48. | Article | PubMed Abstract | PubMed Full Text

103. Thomas GV, Tran C, Mellinghoff IK, Welsbie DS, Chan E, Fueger B, Czernin J and Sawyers CL. Hypoxia-inducible factor determines sensitivity to inhibitors of mTOR in kidney cancer. Nat Med. 2006; 12:122-7. | Article | PubMed

104. Solimini NL, Luo J and Elledge SJ. Non-oncogene addiction and the stress phenotype of cancer cells. Cell. 2007; 130:986-8. | Article | PubMed

105. Garraway LA and Sellers WR. Lineage dependency and lineage-survival oncogenes in human cancer. Nat Rev Cancer. 2006; 6:593-602. | Article I PubMed

106. Chim CS, Wong SY, Pang A, Chu P, Lau JS, Wong KF and Kwong YL. Aberrant promoter methylation of the retinoic acid receptor alpha gene in acute promyelocytic leukemia. Leukemia. 2005; 19:2241-6. | Article I PubMed

107. Masetti R, Vendemini F, Zama D, Biagi C, Gasperini P and Pession A. Alltrans retinoic acid in the treatment of pediatric acute promyelocytic leukemia. Expert Rev Anticancer Ther. 2012; 12:1191-204. | Article | PubMed

108. Garraway LA and Sellers WR. From integrated genomics to tumor lineage dependency. Cancer Res. 2006; 66:2506-8. I Article I PubMed

109. Du J, Widlund HR, Horstmann MA, Ramaswamy S, Ross K, Huber WE, Nishimura EK, Golub TR and Fisher DE. Critical role of CDK2 for melanoma growth linked to its melanocyte-specific transcriptional regulation by MITF. Cancer Cell. 2004; 6:565-76. | Article | PubMed

110. McGill GG, Horstmann M, Widlund HR, Du J, Motyckova G, Nishimura EK, Lin YL, Ramaswamy S, Avery W, Ding HF, Jordan SA, Jackson IJ, Korsmeyer SJ, Golub TR and Fisher DE. Bcl2 regulation by the melanocyte master regulator Mitf modulates lineage survival and melanoma cell viability. Cell. 2002; 109:707-18. | Article | PubMed

111. Garraway LA, Widlund HR, Rubin MA, Getz G, Berger AJ, Ramaswamy S, Beroukhim R, Milner DA, Granter SR, Du J, Lee C, Wagner SN, Li C, Golub TR, Rimm DL, Meyerson ML, Fisher DE and Sellers WR. Integrative genomic analyses identify MITF as a lineage survival oncogene amplified in malignant melanoma. Nature. 2005; 436:11722. | Article | PubMed

112. Rebucci $M$ and Michiels $C$. Molecular aspects of cancer cell resistance to chemotherapy. Biochem Pharmacol. 2013; 85:1219-26. | Article | PubMed

113. Zahreddine $\mathrm{H}$ and Borden $\mathrm{KL}$. Mechanisms and insights into drug resistance in cancer. Front Pharmacol. 2013; 4:28. | Article | PubMed Abstract | PubMed Full Text

\section{Citation:}

Logtenberg MEW and Boonstra J. Cancer stem cells and addicted cancer cells. Oncol Discov. 2013; 1:7.

http://dx.doi.org/10.7243/2052-6199-1-7 